\title{
Investigación de la investigación social
}

\author{
Jesús M. DE Miguel \\ Director del Departamento de Sociología, Universidad de Barcelona \\ OMAR G. Ponde de León \\ Universidad Autónoma del Estado de Morelos, Cuernavaca, México \\ José M. EchavarReN \\ Universidad Pública de Navarra, y Universidad de Panamá
}

\section{RECURSOS DE I+D EN ESPAÑA}

Ya casi en el siglo XXI España mantiene unos niveles bastante bajos de gastos (internos) y de personal en $\mathrm{I}+\mathrm{D}$, sobre todo en el contexto de los países avanzados del mundo ${ }^{1}$. Si se compara España con la media europea la cifras son aproximadamente la mitad. En 1994 los gastos internos totales de I+D como porcentaje del PIB suponen el $0,9 \%$ en España comparado con $1,9 \%$ de la Unión Europea. El personal de I+D como porcentaje de la población activa en 1993 es en España 4,8\% mientras que en la Unión Europea es $9,4 \%$. Unos pocos datos (oficiales de la OCDE) demuestran de forma comparativa el retraso considerable de España en investigación ${ }^{2}$ :

1 Se agradece las excelentes ideas y colaboración de Jordi Cais, y de Xavier Escandell, en especial sobre el cálculo de algunos de los datos de las tablas. También las ideas de Juan Manuel García Jorba, y Raül Tormos durante el curso de 1999. La entrevista original y su transcripción fue realizada por Omar G. Ponce de León, en 1992, para una investigación sobre la Universidad de Barcelona dirigida por Joan Bellavista i Illa. Una versión preliminar de este artículo se presentó como ponencia en el grupo de trabajo «La Sociología hoy: Institucionalización y profesionalización» coordinado por Inés Alberdi, en el marco del Cuarto Congreso Español de Sociología (Madrid, septiembre 1992). La ponencia se reelaboró para la sesión segunda del mismo grupo de trabajo del congreso, sobre «La Sociología académica» coordinada por Josep A. Rodríguez. En su estructura continúa con el artículo de Jesús M. de Miguel titulado: «I+D en Sociología» publicado en la Revista Española de Investigaciones Sociológicas 56 (1991), pp. 167-196; cuya lectura previa se aconseja. La presente versión publicada incorpora numerosas ideas nuevas y entrevistas realizadas durante la primavera de 1999. Email: demiguel@eco.ub.es

${ }^{2}$ Los datos son publicados por el Instituto Nacional de Estadística en su Estadística sobre las actividades en investigación científica y desarrollo tecnologico $(l+D)$. Indicadores Básicos 


\begin{tabular}{lcc}
\hline & $\begin{array}{c}\text { Gastos internos en I+D en 1994 } \\
\text { (como \% del PIB) }\end{array}$ & $\begin{array}{c}\text { Personal de I+D en 1993 } \\
\text { (por mil de la población activa) }\end{array}$ \\
\hline Japón & $2,9 \%$ & 14,3 \\
Estados Unidos & 2,5 & $\ldots$ \\
Francia & 2,4 & 12,5 \\
Alemania & 2,3 & 12,0 \\
Gran Bretaña & 2,2 & $\ldots$ \\
Italia & 1,2 & 6,2 \\
España & 0,9 & 4,8 \\
OCDE & $2,2 \%$ & $\ldots$ \\
Unión Europea & $1,9 \%$ & 9,4 \\
\hline
\end{tabular}

Las diferencias no parecen tan grandes pues están expresadas en números relativos, respecto del PIB y la población activa. En datos absolutos, o per capita, las diferencias son enormes. Es ya un lugar común señalar que el nivel de investigación en España es extraordinariamente bajo, y desproporcionado para el nivel de desarrollo global. Todavía se aplica a veces el "Que inventen ellos» de la polémica de la ciencia española (García Camarero 1970).

En 1994 España gasta 548 miles de millones de pesetas en I+D, aproximadamente el $0,9 \%$ del PIB. Más de la mitad de estos recursos (el 52\%) son financiados por la Administración Pública. Un 41\% lo son por empresas privadas, y el $6 \%$ restante por instituciones extranjeras. Pero la ejecución de estos gastos internos totales es diferente. Casi la mitad (47\%) del gasto se realiza en las empresas; la tercera parte en las universidades (32\%), y la quinta parte restante en la Administración Pública (21\%). El sector público financia aproximadamente la mitad de la inversión en I+D, y también lo ejecuta en ese sector público, pero de forma más intensiva en las universidades que no en la propia Administración Pública. Hay que tener en cuenta que en España -en la fecha a la que hacen referencia estos datos de 1994- hay 40 universidades públicas y sólo cinco privadas. El gasto en $\mathrm{I}+\mathrm{D}$ relativo al sector universitario es $3,5 \%$ en las universidades privadas, con aproximadamente el $4,8 \%$ de los/as investigadores universitarios.

Por campos científicos, más de la mitad de la inversión en I+D se realiza en ingeniería y tecnología (52\%). Sigue detrás en una proporción bastante menor la investigación en ciencias naturales y exactas (19\%), con un cierta especialización en ciencias médicas (13\%) como un campo científico específico. Todas las ciencias sociales y humanas apenas concentran el $9 \%$ del gasto en I+D. Un caso específico es el de las ciencias agrarias con el $7 \%$ del gasto total. Es decir

1994 (INE 1997: 53). La tabla 7 señala el personal de I+D (EDP), es decir en equivalencia a dedicación plena. como porcentaje de la población activa, cuando realmente se refiere a por mil. 
las ciencias duras suponen un $91 \%$ del gasto interno total de I+D, mientras que las ciencias blandas apenas atraen un $9 \%$ de los recursos. Las Ciencias Sociales parten pues de una situación tradicionalmente deficitaria.

El personal de todo tipo que se dedica en España a I+D supone alrededor de ochenta mil personas (concretamente 79.509 en 1994), aproximadamente el 5 por mil de la población activa. De ese total de personal en EDP (equivalencia a dedicación plena, que es como se mide) alrededor de cincuenta mil son investigadores/as (concretamente 47.481 ) es decir el 3 por mil dela población activa española. Pero así como las universidades concentran el $32 \%$ del presupuesto total en I+D sin embargo tienen el $60 \%$ de los/as investigadores (en EDP) del país. Las empresas gastan el $47 \%$ del presupuesto, pero con un 23\% de los/as investigadores. La situación de la Administración Pública es más nivelada con el $21 \%$ de los gastos y el $17 \%$ de los/as investigadores. Esto lleva a una conclusión provisional: que la investigación en las universidades es importante sobre todo en número de investigadores/as, pero bastante más barata que en las empresas ${ }^{3}$.

La investigación en Ciencias Sociales se concentra bastante en las universidades, donde supone el $15 \%$ del gasto en $\mathrm{I}+\mathrm{D}$. De los 173 mil millones de pesetas en gastos internos de I+D en las universidades, en Ciencias Sociales se gastan casi 26 mil millones, es decir justamente un 15\% del total en universidades. Los gastos están muy equilibrados. En 1994 el porcentaje de gastos en Ciencias Sociales en las universidades (se entiende que son públicas y privadas) es:

Gastos corrientes en Ciencias Sociales

Retribuciones al personal:

a investigadores/as

a otro personal

Otros gastos corrientes

Gastos de capital en Ciencias Sociales

Como se ve apenas hay diferencias. Hasta el punto de que hace sospechar que los datos absolutos de las universidades se calculan a partir de la proporción del $15 \%$ en Ciencias Sociales, y no lo contrario.

Pero la proporción de investigadores de ciencias sociales (27\%) es casi el doble que la proporción del gasto total en investigación (15\%), aunque ambos indicadores están lógicamente relacionados. El personal total empleado en

\footnotetext{
${ }^{3}$ Las Ciencias Sociales y Humanidades concentran sólo el $9 \%$ de los gastos internos totales en I+D. Eso supone aproximadamente 173 mil millones de pesetas en el año 1994. La cifra no es muy estable, pues varf́a año a año. En los años ochenta y noventa oscila entre una mínima del $6,5 \%$ en 1987 , hasta un $12,2 \%$ en 1993 . Pero no se observa una tendencia clara al crecimiento. El ciclo se inicia con $8,5 \%$ en 1980 y alcanza $9,3 \%$ en 1994 . Con cambios anuales erráticos no puede considerarse a esto una tendencia al crecimiento.
} 
Ciencias Sociales es el $24 \%$ del total de personal de investigador en las universidades: el $27 \%$ de los/as investigadores y becarios, y el $13 \%$ del resto del personal. En todas las universidades españolas hay 28.591 investigadores (en EDP), de lo/as cuales 7.658 están en las Ciencias Sociales. Esto supone que el gasto por investigador/a es bastante más barato en las Ciencias Sociales que en el resto de la universidad. De media cada investigador universitario (las cifras incluyen siempre a becarios/as) supone 6,0 millones de pesetas al año. Sin embargo, dentro de la universidad los/as investigadores en Ciencias Sociales suponen solamente un coste de 3,4 millones de pesetas. Esto significa que un investigador/a de Ciencias Sociales supone un gasto que es solamente el $56 \%$ de la media de investigadores/as en la universidad ${ }^{4}$.

El gasto en I+D así como los recursos de investigadores y otro personal, es bajo en España. En Ciencias Sociales la dotación de personal es relativamente importante, pero no así los recursos dedicados a investigación. En el total de España el gasto en Ciencias Sociales es el 9\%, en las universidades el $15 \%$, y los/as investigadores en Ciencias Sociales en las universidades son el $27 \%$ del total de investigadores. Sin embargo las diferencias regionales son considerables. El gasto en I+D varía 17 veces entre un mínimo en Islas Baleares, y un máximo en Madrid. Este dato supone dos cosas: primero que las diferencias son enormes, en algo (gasto per capita en $I+D$ ) que se supone que debería variar poco de una Comunidad Autónoma a otra. Segundo, el nivel de desarrollo no explica la utilización de recursos en I+D pues Islas Baleares es la Comunidad Autónoma más rica (en términos de PIB por ejemplo) de toda España. Si se tienen en cuenta sólo las universidades (que gastan la tercera parte de los recursos nacionales en $\mathrm{I}+\mathrm{D}$ ) las diferencias son muy parecidas, con la salvedad de que las diferencias del gasto en pesetas por habitante descienden de 17 veces a 7 veces. En universidades el gasto mínimo es CastillaLa Mancha y el máximo es la Comunidad de Madrid. Las diferencias extremas por Comunidades Autónomas de los otros indicadores apenas varían: son 10 veces (en vez de 11 veces) en investigadores de universidad por habitantes, siendo la mínima en La Rioja y la máxima en Navarra. El gasto por investigador en las universidades varía 2,6 veces comparado con 2,5 veces en el total nacional de todo tipo de investigadores. La mínima en universidades es Navarra que supone 3,9 millones de pesetas por investigador, y la máxima es Baleares con 10,2 millones de pesetas.

Las diferencias de investigadores por habitante son menores pero también considerables, aproximadamente 11 veces de diferencia entre Baleares (la mínima) y Madrid (la máxima). Lógicamente las Comunidades Autónomas que tienen bastantes investigadores, son las que además gastan más, pues

${ }^{4}$ En el contexto de la Administración Pública el gasto total en I+D es 113 mil millones de pesetas, $y$ el gasto en Ciencias Sociales es 3,2 mil millones de pesetas. Esto supone solamente $2,8 \%$ de gasto en Ciencias Sociales. El personal empleado en I+D en Ciencias Sociales es también $2,8 \%$ (solamente 484 investigadores). El papel de la Administración Pública directamente en Ciencias Sociales es bastante reducido. Son las Universidades las que concentran este tipo de investigación/investigadores. 
ambos indicadores están estrechamente relacionados (coeficiente de correlación 0,85 ). Por eso el gasto por investigador/a varía bastante menos, 2,5 veces entre Extremadura que tiene un gasto mínimo de 6 millones por investigador/a hasta el País Vasco que invierte 16 millones por investigador/a. La diferencia de dos veces y media es bastante alta, aunque coincide esta vez con nivel de desarrollo (nivel de vida, coste de equipamiento, etc.).

De estos datos y relaciones se infiere que las diferencias por Comunidades Autonomas son grandes, y consistentes. En el mundo universitario las diferencias son menores, quizás por el efecto de la existencia de universidades públicas, que tienden a nivelar las desigualdades. En cualquier caso el gasto por investigador a nivel nacional es de 11,4 millones de pesetas, mientras que en la universidad es aproximadamente la mitad, 6,0 millones por cada investigador/a. La Tabla 1 presenta los datos básicos de trece indicadores a nivel de las Comunidades Autónomas. Las Comunidades Autónomas están ordenadas de la más rica (Islas Baleares) a la más pobre (Extremadura) según el índice de renta familiar disponible por habitante (para 1993). De esta forma se puede ver a simple vista si la variable desarrollo económico aparece relacionada o no con las actividades en investigación científica y desarrollo tecnológico ${ }^{5}$. Madrid destaca siempre respecto de las demás Comunidades Autónomas en todos los indicadores. Tiene el doble del gasto per capita que la siguiente Comunidad Autónoma (que es el País Vasco); e igualmente el doble de investigadores por población. El número de investigadores totales en España es aproximadamente $48.000,1,2$ investigadores/as por cada mil habitantes. Pero las diferencias son de once veces entre los extremos (de 0,2 en Baleares a 2,6 en Madrid). Es el País Vasco la que gasta más recursos por investigador/a, aproximadamente 16 millones de pesetas al año.

Las universidades gastan aproximadamente un tercio de los recursos totales en I+D (el 32\%). Es un gasto fundamentalmente de las universidades públicas (el 96,4\%), pues las cinco universidades privadas en ese año de 1994 apenas gastan el 3,5\% del gasto total en I+D del conjunto de universidades. Aunque las universidades realizan un tercio de las actividades de investigación en España, hay Comunidades Autónomas con una proporción muy alta: Canarias $72 \%$, Baleares $71 \%$, y Extremadura $66 \%$. La máxima se produce en los dos archipiélagos donde la universidad juega un rol importante en el desarrollo de la investigación. En cambio la importancia de las universidades es mínima en Madrid (15\%), País Vasco (17\%), y Cataluña (27\%) precisamente las regiones del triángulo industrial. En la España industrial la investigación uni-

${ }^{5}$ Los gastos internos en $I+D$ respecto al valor añadido bruto al coste de los factores, sugiere que hay una cierta relación entre desarrollo económico y gasto en I+D. Algunas de las Comunidades Autónoma más ricas -como Cataluña, Navarra, Madrid o País Vasco- efectivamente tienen un gasto mayor en I+D; y entre las más pobres como Extremadura, Andalucía, o Castilla-La Mancha el gasto es bastante bajo. Esta relación no es lineal, pues Comunidades Autónomas muy ricas como Islas Baleares presentan la mínima en gasto en $I+D$. De media en España el gasto en $I+D$ es alrededor de 14.000 pesetas por habitante al año, pero esta cantidad varía entre 2.600 pesetas en Islas Baleares y 40.400 en la Comunidad de Madrid. La convergencia es pues mínima. 


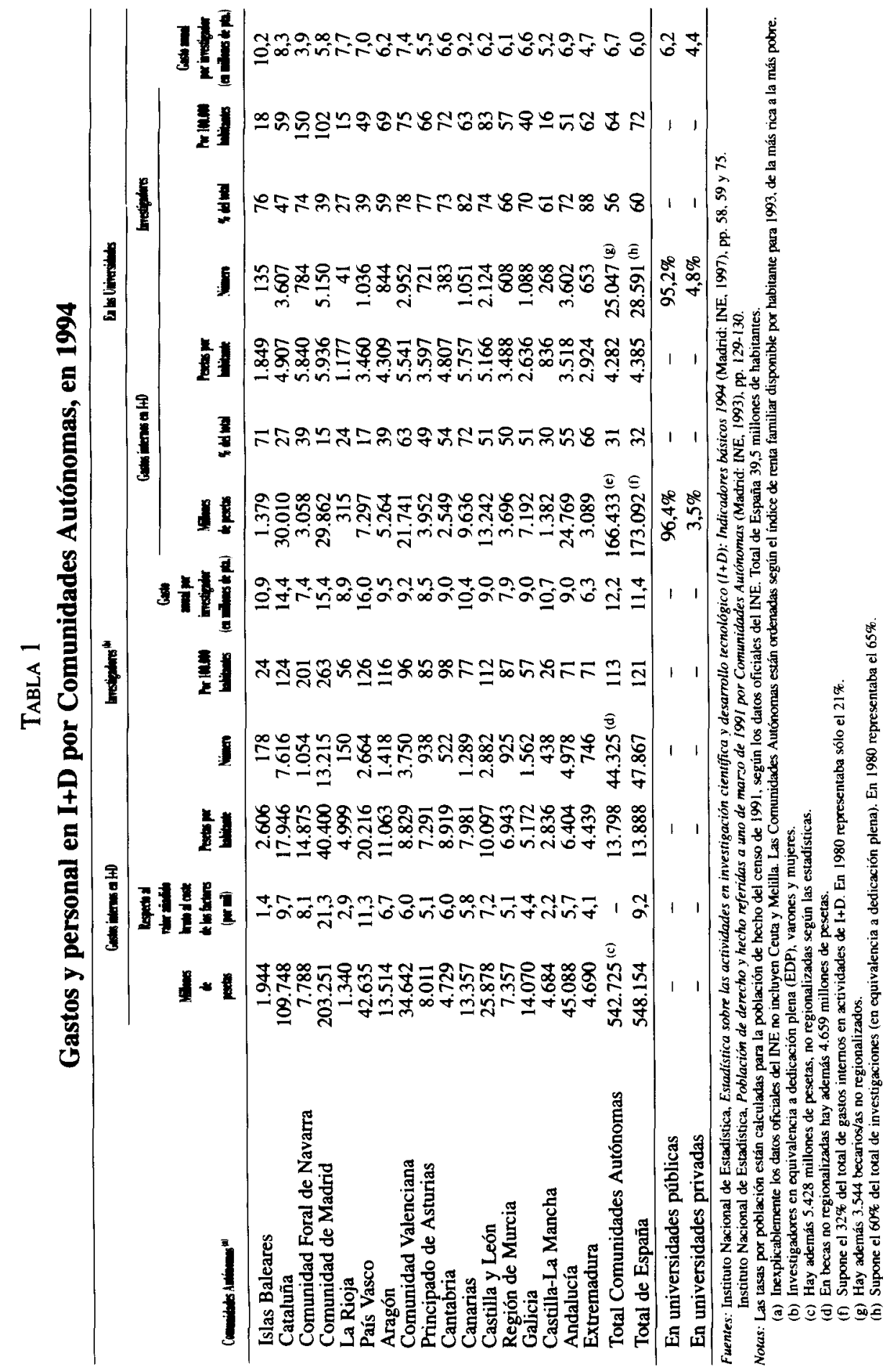


versitaria juega un papel limitado, mientras que en las regiones más de servicios y de turismo la investigación realizada por las universidades es clave. La inversión en investigación universitaria es bastante limitada; supone solamente 4.385 pesetas por habitante al año, con diferencias que son de siete veces de unas Comunidades Autónomas a otras.

En todas las Universidades españolas los/as investigadores-y-becarios son 28.591 en equivalencia a dedicación plena (EDP) lo que representa el $60 \%$ de todos los/as investigadores en España. Teniendo en cuenta que en esas mismas fechas el número total de profesores/as en las universidades españolas es más de 71.000 , esto supone que sólo un $40 \%$ de los/as profesores se consideran investigadores, al menos en EDP. En las Comunidades Autónomas más industriales y desarrolladas, la proporción de investigadores/as que están en la universidad es de las menores: Madrid 39\%, Cataluña 47\%, País Vasco 39\%. En las regiones más pobres la importancia de los/as investigadores universitarios es bastante mayor: representan el 88\% de todos los/as investigadores en Extremadura, y un $72 \%$ en Andalucía. La importancia de la investigación en las universidades es pues inversamente proporcional al desarrollo, aunque las desigualdades regionales son similares a las de toda la investigación.

El gasto por investigador/a al año en las universidades es de 6,0 millones de media. La máxima diferencia se observa entre Navarra (con 3,9 millones por investigador/a) que es la Comunidad Autónoma que sin embargo tiene la máxima de investigadores en España (15 por 10.000 habitantes, comparado con la media española de 7). El coste más alto es el de los/as investigadores en Islas Baleares -con 10,2 millones de pesetas al año- que tiene la mínima de investigadores (menos de 2 por 10.000 habitantes). Se produce pues en las universidades españolas un efecto curioso de redistribución de recursos: si hay muchos investigadores hay poco dinero para distribuir entre ellos/as, y si hay pocos investigadores/as nadan en la abundancia. En las universidades públicas hay bastante más recursos por investigador/a (6,2 millones cada investigador al año) que en las universidades privadas (4,4 millones de pesetas al año), es decir los/as investigadores privados consiguen un $71 \%$ de los recursos que sus colegas del sector universitario público.

La Tabla 2 presenta los estadísticos básicos y los coeficientes de correlación de los trece indicadores: tres sobre gasto, tres sobre investigadores/as, y siete referentes al sector universitario. Se tienen en cuenta siempre las 17 Comunidades Autónomas ${ }^{6}$. Los datos permiten establecer la fiabilidad de los indicadores. El Gráfico 1 presenta las relaciones principales entre los trece indicadores. Demuestra las observaciones realizadas hasta aquí, y sugiere nuevas ideas sobre las desigualdades regionales en I+D en España. Destaca el valor elevado de las correlaciones. Esto se debe a que la mayoría de indicadores están realmente relacionados. Los/as investigadores están lógicamente relacionados con el gasto total en I+D. A su vez la investigación en la universidad es parte de la investigación total, así como los/as investigadores universitarios son parte

\footnotetext{
${ }^{6}$ Sin dar ninguna explicación los datos oficiales (del INE) no incluyen Ceuta ni Melilla.
} 


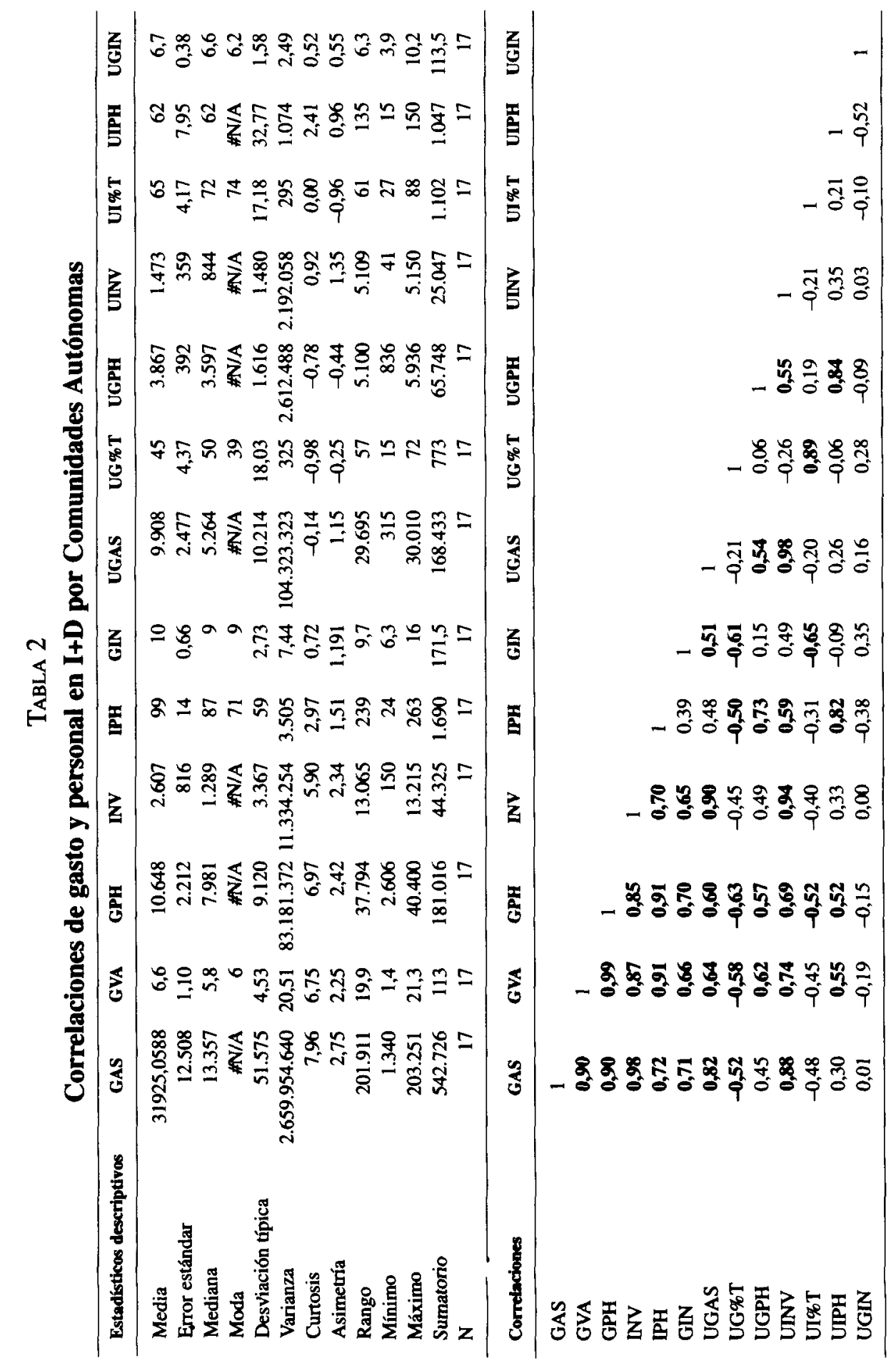




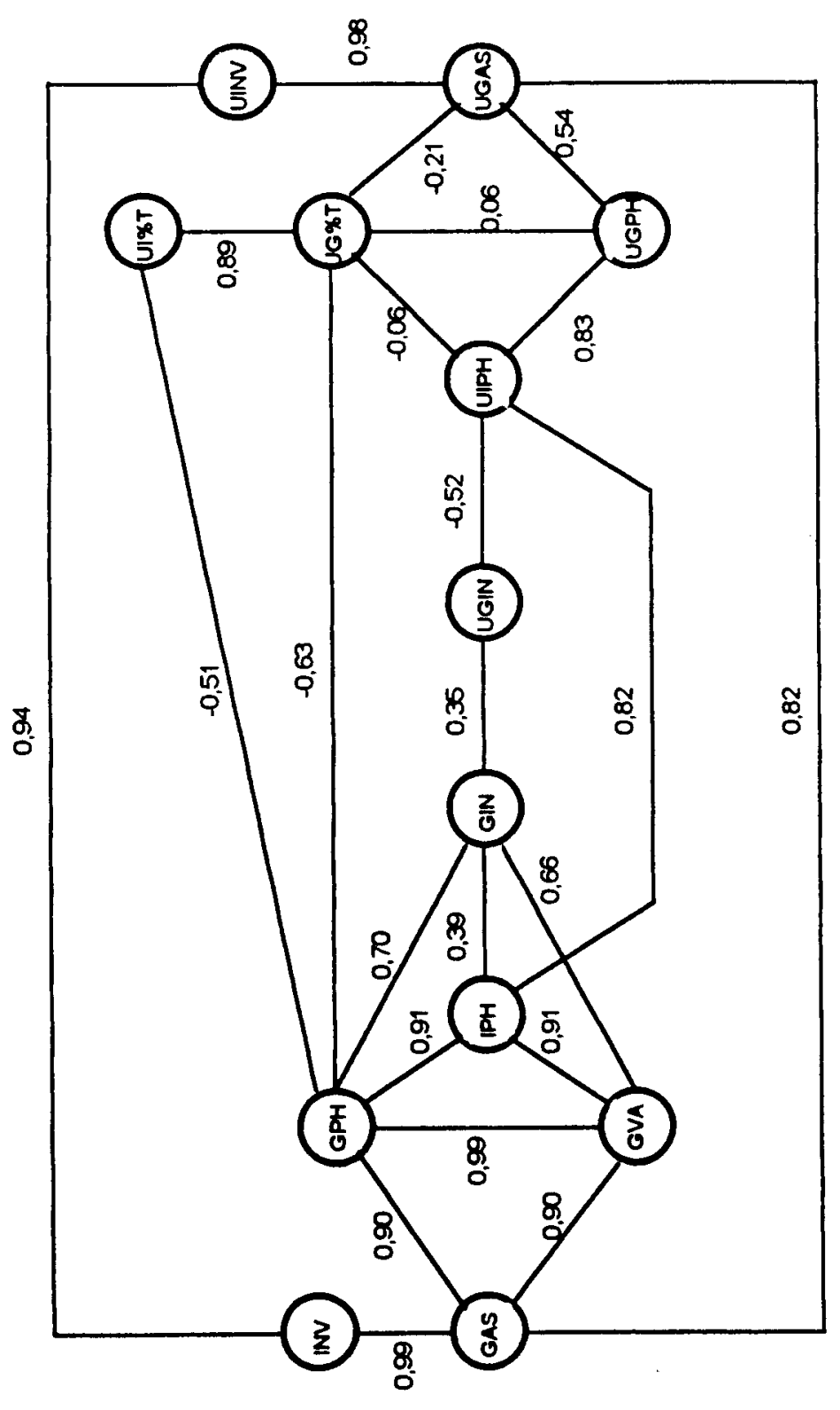

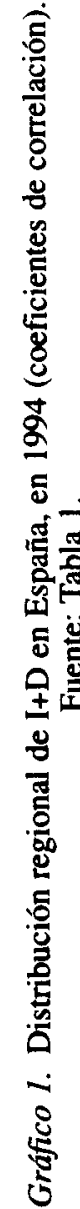


del número de investigadores totales que hay en España. Se observan algunas relaciones interesantes.

El gasto relativo (como porcentaje del valor añadido bruto al coste de los factores) es lógicamente casi la misma variable que gasto per capita. Pero es importante observar que la correlación con la tasa de investigadores es de 0,91 en ambos casos. Hay más investigadores donde más dinero se gasta, aunque no tendría por qué ser exactamente así, pues el coste por investigador varía 2,5 veces $(2,6$ veces en el mundo universitario). Por eso la relación entre la tasa de investigadores (por habitantes) correlaciona sólo 0,39 con el gasto medio por investigador/a. En cualquier caso es positiva, es decir que las regiones con más investigadores/as son además las que más recursos dedican a cada investigador/a. Es interesante observar que la relación entre GIN (gasto por investigador) y UGIN (gasto por investigador/a en la universidad) es sólo de 0,35. Existe una relación positiva, pero el mundo universitario parece regirse por otros factores.

En las universidades cuantos más investigadores hay (UIPH) menor es el gasto dedicado a ellos/as (UGIN) con una correlación de $-0,52$. La relación entre gasto (UGPH) y tasa de investigadores (UIPH) es alta -una correlación de $0,83-$ pero menor que toda la investigación española. El gasto que se produce en la universidad como proporción del total (UG\%T) no tiene relación con la tasa de investigadores en la universidad (UIPH) con una relación débil y negativa de $-0,06$. En el total nacional de I+D el gasto (GAS) y el gasto por habitante (GPH) correlaciona muy alto: 0,90 . La misma relación en las universidades es bastante menor (UGAS y UGPH) de 0,54. Las Comunidades Autónomas que gastan mucho no son necesariamente las que gastan más per capita. La relación entre el gasto (UGAS) y la proporción de gasto de las universidades respecto del total (UG\%T) es negativa: $-0,21$. Las Comunidades Autónomas que dedican un mayor esfuerzo a $\mathrm{I}+\mathrm{D}$ no necesariamente son las mimas que dedican recursos a las universidades (la relación entre GPH y UG\%T es $-0,63)$. La correlación de la proporción de investigadores universitarios (UI\%T) con el gasto total per capita no sólo en universidades (GPH) es también negativa $(-0,51)$.

Las universidades parecen regirse por otros factores que no son los del I+D general del país. Los/as investigadores de ambos tipos (total y universitario) aparecen más relacionados $(0,94$ entre INV y UINV) que el gasto $(0,82$ entre GAS y UGAS). Todo esto hay que tenerlo en cuenta dentro de un panorama de cierta similitud, pues la tasa de investigadores en toda España (IPH) y la tasa de investigadores en la universidad (UIPH) correlaciona 0,82. Es curioso pues que todo correlaciona positivamente, y bastante alto, salvo los indicadores que se refieren a la proporción de gasto o la proporción de investigadores en el sector universitario respecto del total. Tener la investigación muy concentrada en la universidad no es un indicador de desarrollo en $I+D$. Esta afirmación puede parecer excesiva, y por eso debe ser matizada. Pero cuando no hay más investigación que la que realiza la universidad es un signo de debilidad investigadora, y seguramente de falta de productividad. A pesar de ser dos variables relacionadas el gasto per capita en I+D (GPH) y lo mismo 
en la universidad (UGPH) correlaciona 0,57. Para tener importancia la investigación en la universidad (el 32\% del total, y el 60\% de los investigadores en el país) debe de venir acompañado de inversiones fuertes fuera de la universidad.

\section{INVESTIGACIÓN EN LA UNIVERSIDAD}

La investigación es inseparable de la universidad. La capacidad investigadora se empieza a formar durante la licenciatura. Sin embargo, los propios alumnos de Sociología afirman que no poseen «herramientas intelectuales suficientes para emprender una actividad profesional (que incluye la investigación), unida a la sensación de que el personal docente no enseña todo lo que realmente sabe. Salvo excepciones puntuales, se juzga al personal docente come desligado del alumnado, ofreciendo un servicio como mero trámite a un auditorio invisible, sin involucrarse. La sensación de desconocimiento nace de la idea de que hay un conocimiento entre el personal docente sobre cómo investigar, negado al alumnado. Esta interpretación se legitima por el secretismo que recorre la estructura universitaria. La información oficial de cara al estudiante es prácticamente inexistente. Los congresos, charlas, cursos de verano o en el extranjero así como becas, constituyen una oportunidad de formación que el profesorado rara vez transmite. El alumnado percibe que esa información existe, que los profesores/as la conocen, y que no la transmiten" 7 . En realidad una parte del profesorado no comunica cómo investigar pues ellos/as mismos no investigan, incluso es posible que no lo hayan hecho nunca.

Se supone que se aprende a investigar en el tercer ciclo. La denominada "suficiencia investigadora» se consigue a través del doctorado ${ }^{8}$. Existen las becas de formación de personal investigador (FPI) cuyo objetivo es que algunos/as buenos estudiantes se puedan dedicar a tiempo completo a investigar. El objetivo de la universidad sigue siendo el avance y la transmisión del conocimiento. Como señala el informe del International Council on the Future of the University el objetivo es «el descubrimiento metódico y la enseñanza de las verdades acerca de temas serios e importantes» (Shils 1983: 3). La verdad

\footnotetext{
7 Según un alumno de Sociología de la Universidad Pública de Navarra. Entrevista personal.

${ }^{8}$ Un estudiante de doctorado señala: «El doctorando/a no recibe formación oficial extra sobre cómo investigar. Se exige de los estudiantes de tercer ciclo unas habilidades y un salto cualitativo en la calidad de sus investigaciones cuando no se les ofrece formación suplementaria para que sea posible. El doctorando/a se forma a sí mismo a través de pequeñas investigaciones, débilmente guiado por un supuesto tutor. El alumnado aprende verdaderamente a investigar guiado por su director/a de tesis, a la mitad de su doctorado, y de manera informal. Es entonces cuando el hermetismo que rodea al conocimiento se rompe. Han pasado cinco años desde que esa persona entra en la universidad (si es que no repite curso). El desperdicio de energía por parte del alumnado y de medios por parte de la universidad para crear futuros investigadores es patente.» El tono crítico demuestra la dificultad de los/as alumnos de doctorado de Sociología por cambiar la situación.
} 
sigue considerándose mejor que el error. Para ello las universidades cumplen su objetivo a través de dos tipos de actividades: la enseñanza a un nivel de abstracción elevado (la transmisión) y la realización de investigación aplicada (el avance). Se trata de formar profesionales en ambas tareas. La investigación social es doblemente importante pues no sólo trata de reconstruir la estructura de la realidad social, sino que además se dedica a analizas la propia institución universitaria y la profesión de investigador/a. El avance en la ciencia -y en las Ciencias Sociales- supone aceptar los logros y problemas generados por la investigación. El nivel de calidad de una ciencia depende de la autocrítica que genera sobre los contenidos y estructuras de investigación. La Sociología, por ejemplo, es un disciplina altamente crítica, y que desde su nacimiento asume la perspectiva del actor/a. Se considera adecuado analizar la universidad como una organización compleja o formal. Ello incluye investigar el funcionamiento de la investigación, y su aplicación a la realidad social. Es lo que se podría denominar investigación de la investigación. Esta tarea es más apropiada desde lo que se denomina Sociología reflexiva.

La formación en investigación (social) supone la aceptación y lealtad a un conjunto de valores básicos (CVB). El problema de la investigación social es que la profesión investigadora está definida de forma poco concreta. La profesión investigadora suele ser complementaria de otras tareas profesionales, como la docente, gestora, o de administración pública. Existe pues la lealtad a una profesión -por ejemplo, dentro de las diversas Ciencias Sociales- a la vez que la lealtad a una universidad concreta. Ser investigador/a supone pertenecer a un grupo internacional (a veces denominado invisible college) preocupado por la resolución de problemas comunes. A este grupo se le denomina a menudo «colegio invisible» (universidad invisible) o collegium invisible. Se trata de una «agrupación de científicos que mantienen relaciones profesionales e intercambio de los resultados de su trabajo sin que se conozca públicamente su existencia como grupo" (Bellavista 1992: 326). Con el desarrollo de internet, y otros sistemas de comunicación instantánea y globalizante, se aumenta la importancia de ese colegio invisible.

En las Ciencias Sociales españolas -y entre ellas la Sociología- un proceso reciente e importante es el de la profesionalización de la investigación social. Es cada vez más usual encontrar investigadores sociales a tiempo completo. Hasta hace poco se consideraba que la investigación estaba reservada a los mandarines de la profesión (fundamentalmente varones). A veces ellos delegaban tareas de investigación, pero eran esos mandarines los que se responsabilizaban del avance de la investigación social. Cada vez más los proyectos de investigación social aparecen firmados por profesores e investigadores independientes, en escalones intermedios de la jerarquía universitaria. Con los programas de FPI hay incluso personas muy jóvenes, recién licenciadas, dedicadas a la investigación social. Este es un cambio importante en España. Además cada vez hay más investigación social firmada por profesionales fuera del mundo estrictamente académico, o de las universidades. Pero hay pocos programas de formación de investigadores que no sean de docto- 
rado. En Ciencias Sociales los programas de doctorado universitario son escasos, periféricos, normalmente organizados como una cantera endogámica de futuros profesores universitarios. Incluso dentro de la comunidad universitaria más del $10 \%$ de los/as estudiantes de doctorado en una universidad son a su vez profesores de esa misma universidad. Con lo que en las estadísticas aparecen contabilizados dos veces: como estudiantes (de doctorado) y como profesores. Eso conlleva problemas de diverso tipo, y a menudo conflicto de roles.

Se favorece todavía el aprendizaje con un sólo maestro/a, con quien es obligado tener una fidelidad ciega. Los/as estudiantes de FPI lo son de un proyecto de un profesor concreto, y la renovación de la beca depende de los informes favorable de ese mismo profesor/a. Ello puede generar problemas de dependencia, e incluso de inseguridad personal, en los/as neófitos en formación investigadora. La tendencia es a realizar investigación, así como una carrera de formación profesional como investigador/a, como parte del proceso para afianzar el estatus como profesor/a. Se investiga como un paso para conseguir un puesto de profesor/a, o para mantenerlo. Apenas existe una carrera de investigador social (en cualquiera de las disciplinas de las Ciencias Sociales) independiente de otras carreras profesionales. Es posible que en el futuro exista como una opción más.

La carrera de Sociología, por ejemplo, termina normalmente con la obtención del titulo de licenciado/a. Muchos estudiantes creen que su profesión termina con esa licenciatura completada. El doctorado se considera como un apéndice algo extraño, secreto, endogámico, sólo para estudiantes con vocación docente dentro de la propia universidad, o a menudo estudiantes fieles o escogidos. Un estudiante de doctorado de sociología añade: «El hermetismo institucional hace que el doctorado no se promocione correctamente entre el alumnado. No se sabe exactamente qué es un doctorado, para qué sirve, y si realmente desarrolla la capacidad investigadora. Se produce la impresión (nacida del desconocimiento) de que el doctorado se dedica a pensamientos más abstractos, desligados de la realidad social y de la investigación empírica) ${ }^{9}$. Todavía es usual realizar el doctorado en la misma universidad donde se logró el título de licenciado/a, en vez de pensar que lo más lógico es estudiar en otra universidad. También se cree que para seguir un doctorado hay que ser un/a estudiante brillante o genial. No parece un período de formación normal ${ }^{10}$. Incluso a nivel de profesorado se considera a menudo que es una docencia extra (no remunerada) que no cuenta en el plan docente normal. A

9 Estudiante de doctorado de sociología, en una universidad española (comunicación en abril 1999).

10 Otro estudiante de doctorado señala: «Pronto el/la estudiante descubre que la mayoría de los cursos de doctorado son prolongaciones de temas ya vistos durante la licenciatura, tratados (a veces) más extensamente pero de forma igualmente insuficiente (los cursos son de pocos créditos). A menudo la metodología lectiva es similar a la de la licenciatura con lo que la diferencia entre ambas resulta aún mís difusa. La única característica notable del doctorado es que la distancia entre el profesor y c $\Gamma$ ' $\backslash$ tudiante es menor, y es ahí donde nacen las posibilidades de formación investigadora» (abril 1999). 
veces se cree que la investigación en doctorado tiene que ser de altura, muy teórica, poco aplicada, casi sin relación con los problemas reales de la sociedad, lejana a la resolución de problemas concretos, o con metodologías participativas o comunitarias ${ }^{11}$. Afortunadamente cada vez hay más investigación de este tipo, así como comparativa, y sobre sociedades diferentes (incluso dentro de la Sociología) ${ }^{12}$.

La investigación social es cada vez más una tarea independiente, distinta o al menos separable, de la tarea docente universitaria. Desde luego excede de las necesidades educativas de una licenciatura concreta. En otros países la educación de Sociología a nivel universitario logra la creación de una carrera investigadora. En cambio en la mayoría de las universidades españolas la creación de licenciaturas de Sociología es un fenómeno francamente tardío, cuando ya existía una profesión investigadora. La mayoría de los primeros profesores son ya doctores e investigadores por otras Facultades españolas o por otras universidades extranjeras. En algunas ocasiones existieron programas de doctorado antes que de licenciatura ${ }^{13}$. Quizás por eso se tardo tanto en establecer carreras completas de Sociología en España. Muchos de los profesionales se formaron en programas de doctorado en el extranjero. Algunas disciplinas sociales empiezan pues por el tejado.

El modelo universitario español actual, departamental, y el de formación investigadora, es todavía en España bastante piramidal. Una sola persona -el catedrático/a- representa todavía un área entera de conocimiento. Esto ha dificultado la especialización e investigación, pues esa persona tiene que demostrar conocimiento en un área extensa de conocimiento. En las Ciencias Sociales estos catedráticos/as tienen además una tendencia a representar un papel intelectual en la sociedad, con lo que se espera que sean más generalistas aun, y puedan hablar de temas amplios. Los primeros catedráticos de Sociología en España lo son de una asignatura ficticia que se denomina «Sociología general», e incluso alguno se especializa en «Filosofía social». Estos intelectuales tienden a ser levemente investigadores, poco cuantitativistas, y favorecer escasamente la investigación social. La mayor parte del poder dentro de las universidades (rector, vicerrectores, decanos...) está en manos de estos catedráticos generalistas, que se dedican al poder académico pero poco a la investigación. Éstas son explicaciones plausibles para la falta de investigación $-\mathrm{y}$ de investigación

"El libro de Luis R. Gabarrón y de Libertad Hernández Landa, sobre Investigación participativa (1994) es un ejemplo de una nueva metodología social interesante (Libertad fue asesinada por practicarla).

12 Un excelente libro sobre Metodología del análisis comparativo es el de Jordi Caïs (1997).

13 Este es precisamente el caso de la Universidad de Barcelona. En los años ochenta existe ya un programa de doctorado en Sociología que va cambiando de nombre intentando encontrar un mercado apropiado: Sociología, Sociología de las Organizaciones, y luego Estructura y Cambio Social. Existe una cierta especialización y se crea uno específico (y muy exitoso) de Ciencias Sociales y Salud. Pero no existe una carrera de Sociología hasta el año 1992. Al terminar la primera promoción de licenciados/as, en 1996, se crea un programa de doctorado en Sociología Avanzada. El autor primero del presente artículo (J. M. de Miguel) diseñó parte de cada uno de estos programas sucesivos, incluyendo el plan de estudios de la carrera de Sociología en la Universidad de Barcelona. 
social- en las universidades españolas. El cambio más importante de las últimas décadas es el paso del mandarinato autocrático (compuesto por un sólo catedrático por área de conocimiento) al establecimiento lento e imperfecto de Departamentos de Sociología, e incluso de diversos Departamentos de Sociología en una misma Universidad.

La descentralización de la Sociología permite la proliferación de investigación antes incluso que la enseñanza de la disciplina. Algo similar ocurre en otras Ciencias Sociales. La situación cambia, lentamente, cuando en los años noventa del siglo XX, en algunas de las Facultades o Departamentos de provincias (Granada, La Coruña, Santiago, Alicante, Valladolid, Pública de Navarra, Salamanca, País Vasco) empiezan a ganar cátedras personas que a su vez son ya especialistas en alguna rama concreta de la Sociología. Precisamente acceden a la cátedra gracias a su alto nivel de especialización en un área concreta, a menudo la metodología y técnicas de investigación social. Una consecuencia lógica es que en esos Departamentos crean grupos de investigadores en la especialidad del nuevo catedrático/a. Cuando esto sucede $-\mathrm{y}$ en provincias sucede casi siempre si no hay una Facultad específica de Sociología- se reproduce el sistema autocrático de catedrático/a generalista en cada área de conocimiento, repartiendo entre ellos/as los escasos recursos, o creando auténticos reinos-de-taifas.

El problema sigue siendo la pervivencia de Departamentos compuestos de maridajes de diversas disciplinas dentro de esos Departamento de Sociología y... Educación, Metodología de las Ciencias Sociales, Análisis de las Organizaciones, Filosofía del Derecho, Trabajo Social, Psicología, Ciencias Políticas, Antropología, incluso Literatura Española, y Filosofía del Derecho. A veces la combinación es contra natura lo que crea innumerables problemas posteriores. El modelo de un Departamento de Sociología (a secas, sin añadidos) es una estructura imprescindible para el desarrollo de programas de doctorado específicos, así como para el desarrollo de la investigación sociológica. El modelo de dirección de Departamento se convierte cada vez más en un puesto administrativo y de gestión -a menudo odiado- pero casi nunca de liderazgo intelectual o investigador. El director/a de Departamento apenas toma decisiones importantes sobre las líneas de investigación, y se limita a firmar papeles. La investigación parece así desgajada del propio Departamento. En cada caso adopta un modelo distinto, normalmente separado de la docencia y de la gestión del Departamento (ver el excelente artículo de Sánchez-Ferrer 1997).

El tamaño del Departamento, siendo un sólo área de conocimiento (como «Sociología»), es esencial permitir varias líneas de investigación diferentes. Se suelen formar unidades independientes de investigación (unidades vivas, con proyectos vivos, en la jerga usual) que realizan proyectos. Estas unidades o grupos tienen un pie en el Departamento y la Universidad, pero al carecer de locales ad hoc, y para evitar el control del poder universitario, tienen realmente muchas de sus actividades fuera. No existen apenas grupos de investigación investigando dentro de la universidad en Ciencias Sociales. La investigación es especializada y externa, dentro de una panorama de docencia generalista (no especializada). El doctorado es una organización docente, pero poco investigadora. La licenciatura es lógicamente docente no-investigadora. 
Hay muy pocos institutos universitarios de investigación en las diversas disciplinas de las Ciencias Sociales. Algunos de los creados (como el de «Nuevas Tecnologías» en la Universidad Autónoma de Madrid) han desaparecido o han cambiado de orientación. Esos institutos se asemejan más a las estructuras autocráticas de la docencia que no a verdaderos grupos de investigación consolidados. La mayor parte de la investigación en Ciencias Sociales se realiza realmente fuera de la universidad, o por solo practitioners, proyectos de investigación con un/a sólo investigador principal, quizás ayudado por unos/as jóvenes en proceso de formación de personal investigador y becarios/as. Hubo una primera ola de institutos universitarios, o de proyectos de crear institutos, pero se paró. La evolución del esfuerzo ha ido más bien hacia la docencia, sobre todo a másteres y programas de postgrado (algo también a doctorado).

Hasta ahora la investigación en Sociología (y en otras Ciencias Sociales) no se considera una profesion. Suele ser una actividad voluntaria, no remunerada, como mérito para conseguir una plaza de profesor/a. Investiga aquella persona que no puede ser profesor/a (por ser joven, no existir plaza, o tener el título de doctor, o depender todavía de otro profesor). Todavía el Plan Nacional de $\mathrm{I}+\mathrm{D}$, y otros programas similares autonómicos, mantienen una visión peculiar sobre el dinero de investigación. Los/as propios investigadores no pueden cobrar dinero. Se prefiere que no exista personal, y si existe es becario/a, y siempre en situación precaria o de indeterminación. No se sabe si un proyecto va a incluir o no algún becario/a en el futuro. Existe un programa de FPI (becarios/as de formación de personal investigador) pero es escaso y realmente sirve para formar docentes no investigadores. Se comparte la idea de que la investigación sirve para progresar en la carrera docente, pero no como un tarea válida en sí misma.

El Consejo Superior de Investigaciones Científicas (CSIC) es una institución peculiar que merece un estudio aparte. Desde el histórico Instituto Balmes de Sociología, la investigación dentro del CSIC ha supuesto una especialización limitada, con un impacto reducido en el avance del conocimiento sociológico en España. El impacto del CSIC en la investigación sociológica contemporánea es pequeño. Es como si perteneciesen a un grupo distinto. A menudo sirve para la carrera de docentes que no desean enseñar en universidades de provincias (donde ganaron su plaza) y prefieren estar en la plantilla del CSIC. Pero no porque sean vocaciones de investigadores científicas en su origen. En algunos casos sirve para profesores a los que nunca les interesó enseñar, o de otro/as que tienen deseos más o menos legítimos de tener tiempo para sus trabajos particulares. Hay poca comunicación entre las redes de investigadores de las universidades y del CSIC.

Las universidades españolas públicas siguen siendo gobernadas por personas pertenecientes al cuerpo de catedráticos de universidad. Las interferencias y conflictos entre gestión, docencia, e investigación son múltiples. Las universidades suelen ser organizaciones (inmortales) endogámicas. Con el paro, y con los problemas recientes de empleo para científicos sociales, cada vez parecen ser más endogámicas. Esto no debe confundirse con la tendencia 
cada vez mas frecuente de definir plazas de profesorado con perfiles que suponen la concesión futura de una plaza a una persona concreta, con nombres y apellidos. Esta es una práctica corrupta que asegura la promoción interna, endogámica, frente a la posible incorporación de investigadores de fuera ${ }^{14}$. Esto genera una movilidad escasa, y la no necesidad real del mérito (investigador) para conseguir una plaza, sino la fidelidad a un grupo, mandarín, o incluso partido político determinado. Este panorama dificulta seriamente la incorporación de personas con puntos de vista nuevos, innovadoras, con nuevas posibilidades de investigación y docencia. La situación es peor aún cuando un estudiante que consiguió irse a doctorar al extranjero decide volver a España. El problema fundamental es el divorcio existente en las Ciencias Sociales entre docencia e investigación.

De cara al siglo XXI, cada vez se observa una importancia mayor de asociaciones profesionales, congresos y revistas profesionales. Pero no hay un panorama claro respecto a esta actividad asociativa y profesional. No existe una revista oficial de investigación sociológica en España. La más cercana a ese modelo sería la Revista Española de Investigaciones Sociológicas, que es una revista del Gobierno, del Centro de Investigaciones Sociológicas que es el organismo que realiza encuestas de opinión a nivel estatal. Tampoco hay revistas de Sociología española que sean internacionalmente reputadas. Este retraso de publicaciones y de investigación es llamativo. Quizás son innecesarias. Se investiga poco. Mucha investigación es marginal o una excusa para lograr estatus docente. Los/as buenos investigadores tienden a publicar en inglés y en el extranjero. Los/as malos investigadores apenas publican. No existe una demanda de revistas profesionales. Esto está cambiando bastante con la nueva legislación de «tramos de investigación» que supone un sobresueldo limitado, reconocido cada seis años, a los/as profesores que demuestran haber realizado investigación. Pero el sistema está lleno de picardías, y de influencias. Profesores de provincias que realizan investigación local, pero a menudo más imaginativa e innovadora, no suelen conseguir esos tramos de investigación ${ }^{15}$.

Poco a poco la profesión de investigador es más legítima, pero no tanto la organización de la investigación ${ }^{16}$. Nadie tiene ideas claras de si la investiga-

14 Los/as investigadores no pasan de una organización (universidad) a otra dependiendo de su nivel investigador. Se populariza la norma de «el que se fue a Sevilla perdió su silla», o de que cualquier persona de dentro es mejor que cualquiera de fuera, independientemente de sus cualificaciones profesionales. En Sociología apenas salen plazas libres que no se vayan a adjudicar a una persona concreta dentro de la misma Universidad y Departamento. (Tienen bicho, se dice).

15 En las Ciencias Sociales en España ahora la carrera docente y la investigadora van bastante unidas. La labor investigadora vale para progresar en la carrera docente. Casi nunca es al revés. Se ha propuesto a veces que la financiación debería ser un añadido a la carrera docente, como forma de que existiesen jerarquías distintas. Algo se ha hecho en ese sentido con los llamados «tramos de investigación». El sistema va a producir más cambios de lo que parece. Aunque las diferencias de dinero no son muy grandes, y la publicidad es pequeña, los/as profesores se sienten estimulados a publicar, e indirectamente vigilados.

${ }_{16}$ Los primeros congresos de Sociología eran marginales a la profesión. Los primeros presidentes ni siquiera eran sociólogos. Los investigadores y ponentes sí lo eran. Actualmente puede ser al revés. Desde el Cuarto Congreso Español de Sociología (en Madrid en 1992) se puede considerar un congreso institucional de la profesión. El quinto en Granada da origen ya a 
ción sociológica debe centrarse en los Departamentos universitarios, o mejor en los programas de doctorado, o en los institutos universitarios de investigación (que apenas existen algunos), si en el CSIC, en laboratorios o empresas privadas, o en plan free lance. La investigación sociológica financiada por el Plan Nacional I+D, o por el Ministerio de Educación y Cultura, es relativamente marginal. Dentro de las Ciencias Sociales se tiende a favorecer otras disciplinas (Economía, Derecho) y a veces se declara que la Sociología es poco productiva. Las evaluaciones de los proyectos de investigacion realizadas por los/as propios sociologos a colegas suelen ser bastantes negativas. El enemigo parece estar dentro de la propia profesión. Se trata de un modelo de varias escuelas sociologicas en lucha continua.

La investigación de los Departamentos de Sociología suele ser difícil de medir ${ }^{17}$. Lo mismo pasa en las otras Ciencias Sociales. No hay un censo de investigaciones ni de investigadores. Cada profesor/a realiza investigacion dentro y fuera del Departamento (y a menudo a caballo entre dentro y fuera). Es una investigación básica reducida. Se investiga para ganar un cierto dinero extra, no siguiendo una línea de investigación básica bien definida. Se pueden estar investigando temas similares, con puntos de vista homogéneos, por personas diferentes del Departamento sin apenas comunicación entre ellos/as. Hay poca innovación porque además hay poca movilidad. La dependencia del poder docente es elevada. Una proporción importante de esa investigación son informes a instituciones del sector público que dependen de personas del mismo partido político. Cuando cambia el gobierno cambian así los proyectos. Incluso en algún caso se suspenden proyectos ya en marcha. A menudo son informes sociológicos semi-secretos, que muchas veces no son leídos por nadie, o que terminan en un cajón. Muchos de esos informes son de ínfima calidad científica. Dada la eventualidad política de esos informes o estudios sociológicos los investigadores principales no suelen apenas generar estructuras de administración o de gestión. Se utilizan los pocos recursos ya exis-

una presidencia plenamente sociológica y profesional, con fuertes tendencias investigadoras (presidente Juan Díez Nicolás). El sexto en La Coruña elige la primera presidenta (María Ángeles Durán).

17 Un catedrático de Sociología, y director de un grupo de investigación, señala: «La inmensa mayoría de personas que empieza los estudios de Sociología no desean ser investigadores. Tampoco saben nuy bien qué significa eso de ser investigador/a dentro de las Ciencias Sociales. Ignoran que existe esa posibilidad. Pervive la idea de que la carrera termina con la licenciatura y el título de licenciado/a. No se ofrece una información interesante sobre el doctorado, como salida lógica o como continuación del proceso de aprendizaje y de especialización. La mayoría de las personas que realizan el doctorado o empiezan una carrera investigadora (FPI por ejemplo) lo que quieren es un sueldo, una beca, o ser docentes. Incluso bastantes de ellos/as son ya docentes dentro de la misma universidad. La investigación es un requisito -normalmente temporal- para conseguir una plaza de profesor titular de universidad en propiedad. Se realiza el doctorado, incluso se investiga, pero no se construye ni se interioriza el conjunto de valores básicos asociado a investigador/investigación. Para la mayoría de los/as profesores titulares y catedráticos el investigar no es una vocación (en el sentido de 'llamada') sino un sobresueldo, ocasional e irregular, a menudo en forma de especies (bolígrafos, fotocopias, viajes, ordenadores). También sirve como forma de otorgar prebendas a otros colaboradores o profesores más jóvenes y dependientes.» 
tentes para la docencia. Dado que la falta de espacio para ejercer la docencia (despachos de profesores/as) es endémica, no es posible -incluso cuando existe el know how- la creación de laboratorios o grupos de investigación dentro de la universidad. Una medida revolucionaria sería la creación de espacios físicos de investigación (y sólo de investigación) en algunas áreas dentro de la Universidad. Igualmente revolucionario sería la creación de un cuerpo de investigadores que no fuesen becarios/as o en período de formación de personal investigador. Pero ambas medidas, que se discuten a menudo en las comisiones de política científica de las universidades, tienen pocas posibilidades de implantarse. El sistema languidece y la institucionalización de la investigación no se produce de forma independiente.

El doctorado como organización es casi voluntarista. Las universidades españolas no han desarrollado realmente el tercer ciclo, aunque la situación está cambiando aceleradamente. La docencia de doctorado es limitada, y apenas cuenta como carga docente. Si en una licenciatura un estudiante/a tiene que realizar 300 créditos (un crédito equivale aproximadamente a diez horas lectivas) en todo el doctorado se realizan solamente 32 créditos, de los cuales 9 pueden ser de trabajos de investigación, y 5 más convalidados por otros estudios. Un estudiante de doctorado de Sociología reconoce: «Cuando el/la estudiante de doctorado realiza alguna investigación se encuentra con una serie de obstáculos. Por un lado no sabe realmente cómo investigar (no se le ha enseñado), no tiene acceso a bibliografía relevante ya que las bibliotecas españolas están escasamente surtidas en materias de Ciencias Sociales, y no cuenta con un apoyo institucional suficiente» ${ }^{18}$. Muchos profesores/as imparten asignaturas de doctorado a regañadientes. Las clases de la mayoría de programas de doctorado en Ciencias Sociales son irregulares, de horario más limitado que el normal, normalmente por la tarde o «nocturno», sin un sistema de exámenes ni de evaluación de la docencia. Sirva el dato que en las estadísticas oficiales del Gobierno, los/as estudiantes del doctorado no aparecen incluidos en el total de estudiantes.

En Sociología el doctorado es una institución marginal y endogámica. Un estudiante de doctorado señala: «Ello se puede deber a la escasa sensación de pertenencia a una organización, al escaso apoyo institucional que reciben, y que no genera fidelidad al departamento. Si acaso, la fidelidad surge de cara a profesores/as concretos (como la figura del director/a de tesis) que tampoco suelen generar grupos de trabajo integrando investigaciones de otros doctorandos (hay algunas excepciones). La sensación de ser un individuo solo, dentro de una red de la cual no se tiene una perspectiva clara, y de la que no recibe un apoyo concreto, genera un sentimiento de frustración e insatisfacción que se traduce en un número elevado de tesis abandonadas o nunca empezadas realmente. La posibilidad de entablar reuniones periódicas entre doctorandos/as facilita la sensación de pertenencia a una organización más amplia, y la oportunidad de debatir ideas, dudas, compartir información, solucionar problemas, y la posibilidad de formar grupos de investigación, o establecer las

\footnotetext{
18 Abril 1999.
} 
bases para ello. De igual modo es importante establecer una periodicidad en los encuentros del doctorando con el tutor/a o director/a de tesis, con idea de involucrar a ambos en el proceso de formación, de producir más investigación, de contribuir a la formación de grupos de investigadores» ${ }^{19}$. No se evalúa la productividad del doctorado, pero es baja. Se termina la tesis porque se es ya profesor/a o porque se va a perder la plaza si no se presenta la tesis. La motivación de escribir la tesis doctoral como un sistema de avance del conocimiento, y para la formación de una persona de cara a su ocupación en otra universidad es baja. Se quejan los tribunales de tesis doctorales de que el «apto cum laude por unanimidad» es la norma. Eso a pesar de que algunas tesis son impresentables, de mala calidad, formalmente defectuosas, y poco comparables con tesis realizadas en otros países ${ }^{20}$.

La investigación en Ciencias Sociales en España no se considera como un recurso económico o social importante para la Universidad, o para la sociedad global. Las relaciones entre docencia e investigación son extrañas y desequilibradas. En los países centrales la investigación (incluso en Ciencias Sociales, y la ciencia soft) tiene un impacto claro en la economía del país. Pero una parte de esos beneficios vuelven a la propia investigación social en forma de recursos para seguir investigando. No hay programas de doctorado $(\mathrm{PhD})$ ni centros de investigación en Sociología en todas las universidades. Pero es una realidad posible y abundante. En España no es ni lo uno ni lo otro. La comunidad académica defiende su libertad intelectual para seguir dedicándose a temas de investigación marginales (no sobre población marginada, que ese sí que sería un buen tema de investigación aplicada). No se investiga para ser investigador/a. La mayor parte de la investigación social se realiza fuera de la universidad, y de ella sabemos pues poco. El fraccionamiento de la investigación es grande. Apenas existen grupos consolidados de investigación. La comunicación intelectual entre equipos de investigación es escasa. En realidad existen

19 Según un estudiante de doctorado de Sociología, en una de las facultades nuevas (abril 1999). La mortalidad escolar de doctorandos es alta, en el sentido de personas que empieza la tesis y no la terminan, o van cambiando de tema. Eso supone un esfuerzo considerable a los directores, con poca confianza sobre la productividad de los/as estudiantes de doctorado. Hay que tratar de repescar (o salvar del abandono) a investigadores desesperados, desesperanzados, deprimidos, que empiezan a desaparecer del programa. Hay mucha persona ilusionada al principio de una investigación, pero poca que la termina. El problema es que no son siempre las personas más inteligentes las que sobreviven. Tampoco queda claro cómo el doctorado aprende a realizar investigación. Un estudiante de doctorado explica: «El que sea a través del doctorado donde el estudiante/a obtiene la mayoría de edad investigadora (en la forma de la llamada 'suficiencia investigadora') indica el fracaso de la licenciatura. ¿Por qué no es posible que una persona sea capaz de investigar tras ser licenciada? ¿Suponen realmente tanta diferencia los 32 créditos del doctorado frente a los 300 (o más) de la licenciatura? Si esto es cierto, esa diferencia debe ser de orden cualitativo. Esto implica que el profesorado aumenta cualitativamente la calidad de su enseñanza en el doctorado, lo que equivale a decir que la calidad y formación investigadora durante la licenciatura podría haber sido mucho mayor « (entrevista en mayo de 1999).

20 Hay siempre excepciones, como el programa de doctorado especial del Centro de Estudios Avanzados en Ciencias Sociales, de la Fundación Juan March, en Madrid, que es de calidad elevada. 
pocos equipos de investigación -con proyectos vivos constantes- y la investigación sociológica es fundamentalmente individual. Además una proporción de los/as profesores de Sociología universitarios nunca realizan investigación.

La investigación científica en Sociología no está organizada, ni existe legítimamente la carrera profesional de investigador. Tampoco el CSIC ha tenido un papel claro en la institucionalización de una carrera sociológica investigadora de verdad. Las personas no escogen la investigación como carrera. Tampoco eligen el doctorado con criterios profesionales claros. Pero algunas personas terminan siendo investigadores/as, al menos durante una cierta etapa de sus vidas, o como parte de su docencia. Faltan instituciones y locales que acojan grupos de investigación consolidados. En las Ciencias Sociales hay pocos grupos de investigación con líneas de investigación claras. Tampoco hay discusión seria en la profesión sociológica sobre las formas ideales de organización de la investigación social. En las universidades la investigación en Ciencias Sociales es escasa y poco evaluada. También está poco protegida y no existen laboratorios similares a los de las ciencias duras. La investigación de la investigación sociológica no es un tema sobre el que se publique mucho. Conviene tener en cuenta el consejo de que «Algo que afecta el destino de todas las personas tan profundamente como la ciencia no puede permanecer siendo un monopolio de pequeños círculos de expertos, funcionarios, o políticos» (Ben David, 1984: 180). Es pues necesario empezar por investigar la investigación.

\section{INVESTIGACIÓN DE LA INVESTIGACIÓN}

La lista de problemas o temas para investigar la investigación puede ser considerable. Hay que dar contestación al menos a los siguientes ${ }^{21}$ : unidades o grupos de investigación, dimensión adecuada de los grupos de investigación, formación de grupos de investigación, organización del trabajo, factores que afectan positivamente el trabajo y factores que afectan negativamente, estructura jerárquica, unidades vivas y muertas, jefe de la unidad de investigación, potencial de la unidad de investigación, espacio y entorno para investigar, tipos de proyectos, objetivos de los proyectos, proyectos en curso y su evaluación, duración de los trabajos de investigación, y seguimiento de los proyectos. Existen también problemas básicos como los económicos y de gestión, la participación de los/as integrantes de un equipo, banco de proyectos, personas implicadas en actividades de investigación, líneas de investigación, financiación y medios, problemas de información, infraestructura científica, relaciones universidad y empresas, formación de personal investigador, doctorado, tesis, y dirección de tesis. Hay que tener en cuenta temas específicos

${ }^{21}$ Los temas aquí definidos parten de un cuestionario del sociólogo Joan Bellavista a investigadores de la Universidad de Barcelona (Bellavista 1992). Entre la muestra se entrevistó a J. M. de Miguel. Las ideas que aparecen a continuación recogen -entre otras ideas- un resumen de la contestación al cuestionario. 
en las relaciones docencia e investigación, intercambio y movilidad, grupos y relaciones internacionales, formas de evaluar la investigación, así como prioridades de investigación.

Se trata de aplicar estos temas a la investigación en Ciencias Sociales (con un enfoque especial a la Sociología) y a las peculiaridades de este tipo de investigación, en España. Un problema fundamental es el de las unidades o grupos de investigación. En Sociología suelen ser dispersos y poco consolidados. Lo que une a los grupos de investigación de las ciencias duras (Química, Biología, Medicina) es que tienen un laboratorio, hospital, o equipamiento que comparten o les une. En Ciencias Sociales eso es al revés. Los equipamientos no se comparten, y no suele haber laboratorios ${ }^{22}$. Los grupos de investigación pueden ser teóricos y no trabajar sobre una realidad. La unidad suele ser más bien la biblioteca o los ordenadores. A menudo es también la encuesta (o encuestas) o anuarios estadísticos que comparten. Dentro de un mismo Departamento universitario pueden haber diversos grupos de investigación, pero que a su vez se solapan unos con otros incluso en la investigación. Los grupos son además pequeños. Un investigador principal tiene un becario/a de FPI, y quizás colabore algún otro estudiante de doctorado. Pueden haber varios profesores asociados en una investigación, pero a menudo es una colaboración más teórica que real. Un equipo muy pequeño (de dos personas) puede constituir un grupo de investigación adecuado. Otros investigadores realizan su investigación con otros centros fuera de la Universidad ${ }^{23}$.

Saber cómo se forma un grupo de investigación en Sociología suele ser un misterio, pocas veces puesto por escrito. Lo más reciente es la agrupación de profesores de la misma universidad en un proyecto de $\mathrm{I}+\mathrm{D}$ financiado por organismos públicos (como el Plan Nacional, la CICYT, los programas nacionales, el Programa General del Conocimiento, etc.), o por fundaciones privadas algunas de las cuales utilizan sistemas similares. Existe un cierto debate y preocupación sobre los becarios/as de investigación. Un proyecto puede

22 Ésta es la carencia más importante de la investigación social en la universidad. Es preciso pues crear laboratorios de Ciencias Sociales. El problema es que el sistema de organización es más individual que institucional. La investigación gira en torno a personas concretas, no a organizaciones. Suelen funcionar al revés: en vez de ir todos/as a un laboratorio a realizar investigación un grupo de investigación se caracteriza porque sus miembros salen afuera a realizar investigación, trabajo de campo, o pesquisas sociologicas.

${ }^{23}$ La definición de «grupo de investigación» es peculiar, y seguirá siéndolo durante bastante tiempo, en tanto no tenga un espacio físico común donde efectivamente se realiza investigación dentro de la universidad. No hay una fórmula mágica para decidir la dimensión adecuada de un grupo de investigación. Depende de la investigación que se está realizando. En Sociología el grupo es más pequeño de lo que parece. Pero en los casos de estudios de encuesta las personas que efectivamente trabajan para un proyecto son bastantes más pero en un trabajo especializado ( $\mathrm{y}$ temporal). En muchas ocasiones quienes dirigen el trabajo de campo no son las que realmente realizan el estudio ni las que redactan el informe final. Hay una contratación externa, normalmente con salarios bajos. Cada vez la encuesta está condicionando más la investigación social, elevando el coste, el número de personas que trabajan en un proyecto, pero también el interés y el estatus de la investigación sociológica final. 
solicitar un becario/a con cargo al proyecto, pero generalmente se concede en otra convocatoria. Pero para que una persona consiga una beca cada vez es más importante el requisito de que se anexione a un proyecto concreto. Hay estudiantes de doctorado sin beca realizando la investigación de tesis doctoral. Aunque no hay datos accesibles la impresión es que los/as estudiantes becados terminan la tesis más a menudo que el resto de doctorandos no-becados. La visión es casi autobiográfica: los doctorandos sin beca están más desmotivados. Dudan que el doctorado les vaya a resultar rentable en el futuro cuando no lo está siendo en el presente. La clase social discrimina en el grupo de los doctorandos no becados. Las clases sociales más bajas son las que se desaniman antes, ya que carecen de un entorno y una socialización que valore el conocimiento por sí mismo, y que muestre la utilidad económica futura de invertir en un doctorado» ${ }^{24}$. La dirección de tesis doctoral sigue siendo otra relación poco clara. Muchas personas que forman la dirección de tesis en realidad no la dirigen. $Y$ algunas personas que no constan como director/a de tesis en realidad sí que dirigen una investigación doctoral. Las líneas de autoridad y las de influencia profesional suelen ser algo distintas. Un problema adicional es que en Ciencias Sociales bastantes personas que dirigen investigaciones no investigan actualmente (algunas no han investigado nunca). Algunos/as directores no saben escribir, no saben citar apropiadamente, no han publicado investigación original. Entonces es una misión imposible. Pueden ser personas excelentes, e incluso animosas, pero son incapaces de enseñar investigación. Es imposible que una persona que no ha investigado (ni escrito investigación) enseñe a investigar. La situación es más frecuente de lo que algunas personas creen, y los investigadores/becarios jóvenes no suelen saber distinguir.

En las ciencias duras -al menos en la imagen que tienen los sociólogos/as de esas ciencias duras- la investigación se realiza porque hay unos campos definidos. El investigador/a principal define las líneas de investigación, y dirige la investigación. Los becarios/as tienen que asumir la investigación que se realiza en el Departamento o en un laboratorio concreto. Incluso las tesis doctorales se refieren directamente a la investigación que se realiza en el laboratorio. En las Ciencias Sociales eso no suele suceder. Son los doctorandos, incluso los más jovenes, quienes definen sus propios temas de investigación. Posteriormente piden a un profesor/a que acceda a dirigirles la tesis. Es pues más un sistema de patronage que no un sistema de dirección de investigación o de definición de líneas estructuradas. Esta situación supone dos cosas en las Ciencias Sociales; primero, que la dispersión de tesis en un Departamento suele ser considerable. Un Departamento raramente es conocido por avanzar

${ }^{24}$ Según un doctorando de Sociología en una de las nuevas Facultades, en abril de 1999. Una paradoja es que el futuro de una persona como investigador (o como profesor) suele depender poco de las notas que haya sacado durante la carrera, a menos que sea realmente brillante. Las notas son el baremo principal para conceder becas. No se analiza la falta de relación entre notas y productividad posterior en la investigación social. Quizás las calificaciones universitarias no estén bien realizadas, o hay otros factores intervinientes importantes, como motivación o conocimiento de idiomas (sobre todo inglés). 
el conocimiento en una línea determinada. Segundo, hay tesis marginales, que no contestan a preguntas relevantes dentro de la ciencia. Quizás el sistema permita una mayor innovación, pero seguramente tampoco de forma excesiva. Hay poca acumulación de conocimiento.

Es difícil definir la organización del trabajo de investigación en las Ciencias Sociales. Como el trabajo se hace fuera de las fronteras del laboratorio, e incluso fuera de la universidad, no hay una contabilidad clara de horas trabajadas, ni del sistema de funcionamiento. Otros becarios (sobre todo en las ciencias duras, y en los laboratorios) tienen un horario claro. En Ciencias Sociales se produce una indefinición del trabajo de un becario/a. Si se les hace trabajar en proyectos de investigación se sienten explotados. Se supone que deben de trabajar en su tesis doctoral, cosa que en general tampoco se hace con un horario preciso. $\mathrm{La}$ falta de locales dentro de la universidad impide un funcionamiento claro. Al no haber laboratorios tampoco hay locales que puedan servir de puntos de reunión, quizás porque se entiende que son innecesarios. Pero es un poco al revés. Dada la dispersión de temas de investigación, y la ausencia real de investigación son más importantes aún los lugares comunes de comunicación y debate. Una forma de mejorar la investigación en las Ciencias Sociales es que exista ese espacio, al menos a nivel de investigadores jóvenes y becarios/as. El trabajo diario actual se organiza actualmente más en forma de uno a uno, de director de la investigación a becario/a, de forma más aislada. Esta forma de organización parece que funciona para las Ciencias Sociales. Quizás no haya que tomar el modelo de las ciencias duras. La mecánica del trabajo se realiza informalmente. Permite más comunicación con el exterior, y menos lealtad al grupo (al supuesto laboratorio). El investigador/becario acude cuando cree que debe hacerlo, y las pautas varían mucho de uno a otro/a. Normalmente viene cuando tiene problemas: cuando le han censurado un cuestionario, no le sale una técni$\mathrm{ca}$, o no encuentra una estadística importante. Acude entonces a un/a investigador principal. Los investigadores/becarios jóvenes demandan información o consejo precisamente cuando lo necesitan. Teniendo en cuenta que no hay territorio (locales o despachos) el sistema de organizacion es bastante adecuado. La situación cambiaría bastante si existiesen esos locales.

Hay factores que afectan positiva y negativamente el trabajo de investigación. Un factor positivo de trabajo de investigación es que los investigadores/becarios trabajen juntos o sepan que existen. La moral de grupo es importante. Las reuniones cumplen a menudo una función simbólica. Lo más importante es saber qué están investigando las demás personas. Otro factor importante es la definición de normas informales, como la terminación de tesis doctorales y de investigaciones. Los/as colegas se dan cuenta de que otros colegas no sólo empiezan investigaciones sino que además las terminan. La comunicación aunque sea informal es bastante positiva. También es importante informar que las personas que terminan su investigación obtienen un trabajo, más estatus, un salario más alto (o más seguro), un puesto de trabajo mejor ${ }^{25}$.

${ }^{25}$ La carencia de espacios propios de investigación es uno de los factores que condiciona más la investigación social. Hay que competir por el espacio, lo que es común a cualquier otra 
En Sociología no existe un protocolo o sistema de formación. Los/as estudiantes de doctorados o becarios que vienen con un proyecto personal de investigación es porque tienen ilusión de realizar una investigación. Normalmente no saben por qué tienen ilusión para hacer esa investigación. Posteriormente no saben cómo llevarla a cabo. Aunque supieran investigar no saben ponerlo por escrito. Quieren investigar pero tienen ideas extrañas de cómo expresar unas hipótesis, cómo realizar un trabajo de campo, diseñar una muestra, o realizar un cuestionario. El programa de doctorado no enseña a investigar. Al no haber un laboratorio no existe un sistema de formación en investigación claro. Pone demasiada presión sobre los/as directores de investigación, que tienen que educar a los/as jóvenes investigadores o becarios de uno/a en uno/a. Todo eso sucede con poca confianza en el éxito final. Es un sistema que desperdicia muchos recursos. No hay apenas formación de unos becarios a otros, entre ellos/as ${ }^{26}$.

El ser investigador/a se valora poco porque no existe una carrera investigadora profesional. Es difícil empezar de investigador y terminar de investigador principal (o de profesor de investigador en la terminología del CSIC). Normalmente se entra lateralmente; un/a investigador principal llega a serlo a través de conseguir una cátedra de universidad o una plaza de profesor titular de universidad. En el CSIC se entra de profesor de investigación no como una carrera de investigador, sino a menudo como una forma para no tener que desplazarse a otra universidad a enseñar. En Ciencias Sociales es usual ocupar esos puestos por personas que políticamente tienen que residir en Madrid, $e$ incluso que han sido rechazados por alguna universidad determinada. Las Ciencias Sociales incluyen especialidades bastante sensibles a este tipo de problemáticas políticas. La carrera de investigación (FPI, o becario, por ejemplo) se utiliza normalmente para pasar a profesor -ayudante, asociado, titular de escuela, titular de universidad- y de ahí a catedrático/a. En la carrera de muchos catedráticos el ideal es dar pocas clases, delegar en ayudantes, incluso reservarse para el doctorado (aunque luego tampoco se dedican mucho a doctorado). Hay catedráticos/as que apenas si dan clase. Así que el profesor tiene como ideal pasar a cate-

organización. Los recursos suelen ser escasos, sobre todo en la universidad. Se aprende a competir por los espacios, a negociarlos con los gestores, y a reservar espacios incluso en tiempo de menos investigación. En Ciencias Sociales hay bastantes investigadores que no tienen un espacio que puedan identificar como suyo. Esto sucede sobre todo con los más jóvenes o los que no trabajan como docentes. Un problema grave en Sociología -no tenemos datos de si existe en otras disciplinas- es que hay bastante gente que empieza y poca gente que termina. Se trata de la mortalidad de investigadores. En parte se debe al sistema de selección de investigadores.

26 En Ciencias Sociales la investigación suele ser un paso o factor positivo para pasar a la docencia y pocas veces lo contrario. La mayoría de las personas empiezan a investigar no por vocación, sino porque no consiguen un puesto de profesor/a. Si lo consiguen no investigan, o incluso nunca terminan el doctorado. Quizás sea positivo que no existan tantos puestos de profesor accesibles porque obliga a investigar y aprender a investigar. Una persona que aprende (aunque sea obligadamente) a investigar reproduce luego esa conducta investigadora; a menudo durante toda su vida. Pero en Ciencias Sociales no hay apetencia por investigar, sino por conseguir un puesto de trabajo seguro, aunque sea mal pagado. 
drático no sólo por el estatus (y el salario añadido) sino para dedicarse de pleno a la investigación, la diseminación del conocimiento, para dedicarse a la política, o para ganar dinero extra fuera de la universidad. En realidad suele ser una combinación de todas esas variables. Es una verdadera contradicción. La carrera de investigador/a aparece normalmente truncada, con entradas y salidas frecuentes a la vida política y de gestión (universitaria entre otras instituciones) que debilitan la trayectoria investigadora.

En la investigación, la estructura jerárquica no suele ser excesivamente autoritaria ni piramidal. En las Ciencias Sociales eso es menos aún. No suele haber un/a jefe o director de grupo de investigación claro. Hay personas que tienen proyectos y que dirigen proyectos (son investigadores principales). Pero en el contexto del Departamento las Ciencias Sociales tienden a democratizar -a menudo hasta la ineficacia- la organización investigadora. Se aplica la jerarquización docente, con los diversos cuerpos de funcionarios. Se solapan las dos estructuras organizativas (de investigación y docente) dominando usualmente la docente. En el caso de investigaciones individuales (como las de los doctorandos/as) las relaciones son incluso más paternalistas. Depende más del director de tesis, y es más unívoca. Los becarios/as (doctorandos) eligen sus propios temas de investigación y la forma de realizar la investigación. Todas las personas se tutean. Es usual que investigadores principales sean criticados abiertamente por doctorandos y por las personas que empiezan a realizar investigación. Realmente apenas hay jerarquía. La jerarquía simbólica puede ser más dura que la organizativa, precisamente porque la de tratamiento personal es estrecha. La jerarquía investigadora coincide mucho con la jerarquía docente, ya que no hay un escalafón o cuerpo legítimo de investigadores. Esto supone más problemas que beneficios. Desde una observación exterior (o desde otras ciencias) puede parecer que no se está haciendo investigación de calidad, o que el grupo de investigación no existe. Pero sí se está haciendo investigación innovadora, y el grupo existe. Lo que pasa es que es un grupo bastante más lábil, más multiforme, y múltiple. Hay pues funciones positivas en el sistema de organización de la investigación social que no conviene eliminar ${ }^{27}$.

Como en las demás ciencias, la persona que investiga depende mucho -incluso a nivel personal- del director de tesis o de investigación. Le es difícil cambiar de director, y generalmente supone un coste profesional considerable. Una vez escogido director de tesis una persona se alinea en una escuela o grupo determinado. Le sería costoso cambiar a otro. Los/as doctorandos viven obsesionados con la elección de director, y no tanto con la del tema de investigación. Un/a director de tesis es más un buscador de recursos, dinero de

${ }^{27}$ Casi cada investigador (o becario/a) es en sí mismo un director/a de proyecto. Puede que no sea un proyecto de $\mathrm{I}+\mathrm{D}$, pero realmente puede haber en un Departamento tantas investigaciones como investigadores/as. No hay personal sin trabajar, porque el personal no investigador (el «otro personal» de las estadísticas) apenas existe en las Ciencias Sociales. Hay también poco trabajo secretarial o administrativo, y suele ser cubierto (mal) por el personal de servicios y administrativo del propio Departamento. Si la obtención de datos se complica suele ser una actividad que se delega o que se subcontrata. 
investigación, facilitador de un trabajo, escritor de cartas de referencia, etc., que no realmente un director de tesis. Pero eso sucede en todos los países del mundo, y en todas las universidades conocidas.

El potencial de un grupo de investigación es complicado. El problema es que mucha investigación se realiza fuera de la universidad. Es complicado conseguir entonces que la investigación que realiza el grupo sea unitariamente competitiva a nivel internacional. El problema es que mucho personal que está en el Departamento ha decidido hace ya bastante tiempo investigar fuera del Departamento. Si no hay espacio, ni organizaciones, ni carrera profesional de investigador, ni recursos claros, ni laboratorios, es complicado reconstruir un grupo de investigación con potencial internacional. El Departamento/Universidad no provee espacio, ni luz, muy poco teléfono, escasos sistemas de reproducción... sin embargo maneja o controla el presupuesto, se queda con el overhead (el porcentaje de proyectos de investigación), y se apropia de algunos de los éxitos del grupo de investigación. La situación es desequilibrada y proporciona poca ayuda para institucionalizar grupos de investigación social.

No hay una razón clara para que un/a buen investigador social decida investigar en la universidad. Apenas se incentiva la investigación social, que es de un carácter diferente de otras ciencias. Lo deseable es que una persona adquiriese más estatus o nivel (y salario) en base a realizar buena investigación. Un problema adicional es quién evalúa la calidad de esa investigación. Pero eso apenas ocurre. La segunda forma de incentivar sería el establecimiento de locales, despachos, edificios equipados, de tal manera que no mereciese la pena salir de la universidad para realizar investigación. La tercera posibilidad es que hubiese investigación promovida por la propia Universidad. Es llamativo, por ejemplo, que no exista investigación sociológica sobre la propia universidad, o sobre las empresas que dependen o colaboran con la universidad. El potencial de los buenos investigadores/as está desaprovechado, pero la organización universitaria no sabe como aprovecharlo. Tampoco lo investiga.

El espacio y el entorno para investigar en Ciencias Sociales en las universidades públicas es inexistente. Se carece de espacio para investigación; es para docencia. Incluso hay poco espacio para programas de doctorado o su gestión. En un espacio docente de licenciatura (o diplomatura) sólo se investiga como algo adicional, secreto, anónimo, sin espacio. Se dice que la persona que investiga es que le da por ahí, porque le gusta, es una manía que tiene, porque así presume delante de amigos/as o vecinos/as, por mantener un estatus más alto, quizás incluso porque tiene vocación intelectual. Pero no porque haya espacio; más bien hay un espacio para no investigar. Se establecen estructuras de control para no investigar, para no motivar estudiantes interesantes, para no premiar diferencialmente el esfuerzo académico. Si además no hay suficientes metros cuadrados para la docencia difícilmente se pueden reservar unos cuantos metros cuadrados exclusivamente para investigación ${ }^{28}$. En el

${ }^{28}$ Pero el entorno es bastante adecuado. Las Facultades suelen ser interesantes, llenas de mentes inteligentes (profesores y estudiantes), y el ambiente intelectual puede ser imaginativo. 
caso español falla la infraestructura. Tendría que ser una organización autónoma, paralela a la docente. El espacio y recursos docentes se mezclan con los investigadores. Hay poco investigador/a neto en la universidad. El tiempo y espacio que se tiene para investigar (por ejemplo para escribir el presente artículo) es además de otras responsabilidades docentes que se tienen en la Universidad. El misterio es qué es lo que hacen en su tiempo libre los/as profesores que no investigan. El espacio/tiempo de investigación no recibe un pago adecuado (a menudo ningún pago) ni recompensa. Dadas las dificultades, mucho investigador que empieza a investigar se desanima y lo deja. Las personas que no empiezan a investigar al inicio de su carrera académica normalmente no investigan nunca.

En la investigación social se distinguen bastante bien dos tipos de proyectos. Uno es el que al investigador/a le pagan por realizar. El otro es el que el investigador/a desea realizar por si mismo para hacer avanzar el conocimiento. Se puede diferenciar entre investigación aplicada y básica, pero esa distinción no está tan clara en las Ciencias Sociales. Mucha investigación viene de otros colegas, de partidos políticos afines, de organizaciones relacionadas con la universidad. El proyecto suele ser confuso, pero suele especificar el equipo, los recursos, y las conclusiones. Son proyectos poco científicos, normalmente poco intelectuales. Pero hay mucho investigador social universitario que vive de esos proyectos. Se realizan por dinero, o por fidelidad a una bandería política determinada. Se llevan a cabo también para conseguir poder. Los otros tipos de proyectos son más bien de doctorandos/as que quieren realizar una tesis doctoral determinada, o de profesores/as que desean vivamente desarrollar una línea de investigación determinada. Gracias a la financiación ministerial y de la CICYT cada vez este tipo de proyectos son más numerosos. Hay otros tipos de proyectos minoritarios. Son, por ejemplo, los proyectos de investigación que se presentan de estudios que ya se han realizado previamente, y que se duplican. También están los premios y concursos en el caso de investigadores con más estatus que ya no obtienen motivación de realizar proyectos comunes sino aquellos que además tienen un reconocimiento nacional.

Muchos proyectos están concedidos antes de ser diseñados. Son los de encargo. No merece la pena pensar mucho, y no se suele elaborar demasiado el proyecto antes de presentarlo. Se suele seguir un protocolo que ha sido presentado por el propio contratador. Como el proyecto ya está dado de antemano no se necesita de genialidad científica para obtenerlo. Es en el segundo tipo - de proyectos que se adecuan a líneas de investigación propias- en donde los proyectos son más competitivos. Una investigación interesante sería analizar porqué razones los/as investigadores desean realizar ese tipo de proyectos. «Es difícil conseguir apropiadamente los objetivos de la investigación» señala un doctorando en Sociología. Se suele conseguir un proyecto que no cubre toda la investigación, o que se realiza luego de forma incompleta. Se

No falta espacio. Si hubiese más espacio se notaría que bastantes profesores no trabajan ni investigan en la universidad. Incluso que hay profesores que apenas pisan la universidad, y sobre todo que no trabajan allí. 
vuelve a presentar como proyecto, $o$ incluso da origen a alguna tesis doctoral colateral. A menudo tampoco entonces se realiza adecuadamente. Es parte del propio proceso de investigación que no se acaba nunca. Las primeras ideas y bocetos no suelen estar financiados. Es en un segundo intento que un proyecto que ya se había empezado a desarrollar obtiene una financiación adecuada. Otras veces se trata de una política de Robín Hood, o de robar a los ricos para dárselo a los pobres. Eso en investigación social es bastante común. Suele ser una decisión importante en Sociología donde normalmente los investigadores/as financian sus propios proyectos de investigación con dinero y recursos (equipamiento) de los proyectos de encargo. Al revés no suele suceder. Con los proyectos de encargo, que se realizan más bien por dinero, si el/la investigador principal es valioso se terminan financiando los proyectos de investigación más audaces e innovadores, que tendrían problemas para ser apoyados económicamente en los mercados comerciales. Al menos se realiza una primera investigación inicial, que permite luego presentar otro proyecto quizás con ideas más comerciales.

En Ciencias Sociales los objetivos del proyecto suelen estar más claros que la metodología. La metodología, el diseño de la investigación, suele ser una parte difícil de desarrollar. Se trata de definir bien los datos que se van a utilizar, la muestra de eso datos, el sistema de análisis causal que se va a generar, etc. Los objetivos suelen estar claros en la mente de los investigadores. Pero luego la realidad es bastante distinta. No se siguen las etapas prefijadas (si es que alguna vez se fijaron) ni los calendarios. La evaluación del proyecto en curso suele ser intuitiva. Se sabe más o menos cómo se está realizando el estudio, y cuánto retraso se lleva. Lo importante es saber cuando parar el trabajo de campo o la recogida de datos, y pasar al análisis. La mayoría de los estudios se realizan por oleadas: momentos de poca productividad y otros de actividad frenética. El que la planificación del desarrollo del proyecto se realice a ojo no significa que se haga mal.

Cada vez más los proyectos incluyen cronogramas y calendarios por etapas y actividades. La realidad es luego bastante diferente, más prosaica. En la investigación sociológica no se suele utilizar PERT, ni caminos críticos, ni Research Planning Diagrams, etc. Eso se suele utilizar para vender u obtener un proyecto o contrato. Se incluyen por ejemplo cronogramas. Cuando se evalúan muchos proyectos se entiende que estos cronogramas se incluyen para dar un sentido de seriedad. El investigador/a desea obtener el proyecto. Pero queda bastante claro que el propio investigador/a no cree en el cronograma, y que suelen ser de una ingenuidad considerable. A menudo las etapas más importantes no aparecen. El final del proyecto se sitúa a veces con la obtención de los datos, sin contar con mucho tiempo para el análisis ni para la redacción del informe. Luego la realidad es que la redacción puede llevar tanto tiempo como el resto, si realmente se realiza una investigación seria.

Hay toda una serie de mitos sobre la duración de un trabajo de investigación. En la investigación social los problemas suelen ser dos: la neurosis del empezar, y la eternización en terminar. A menudo los/as investigadores hacen todo lo posible para no empezar su propia investigación, sobre todo para no 
empezar seriamente a escribir. Este problema se observa sobre todo en los/as investigadores noveles, y en concreto en las tesis doctorales. Leen mucho, siguen leyendo, vuelven a leer. El índice o esquema de la investigación cambia. A veces cambia el tema entero varias veces. No están de acuerdo con lo que leen. El problema es que la capacidad de leer sobre un proyecto es infinita. La angustia por empezar se autoalimenta cuanto más se lee. La otra cara de la moneda es la eternización en terminar. El proyecto una vez empezado no prospera, no se sigue, no se desarrolla. El seguimiento real suele depender más de la presión del contratador o de la universidad, de los plazos por cobrar, de la terminación de la beca. Quizás sería útil que la universidad controlara los calendarios de realización de los proyectos de investigación. Esto sería un favor doble, pues los equipos de investigación producirían más. Es típico que los/as becarios realmente empiezan a escribir la tesis de verdad cuando se les acaba la última mensualidad de la beca, ya sin posibilidades de renovación. Mientras tanto van estirando la investigación, o dicen que están investigando pero sin producir demasiado por escrito. Un papel del director de tesis (desagradable pero útil) es precisamente ponerse muy estricto con los plazos de entrega de materiales escritos. La (supuesta) calidad suele ser la excusa para no entregar materiales.

El seguimiento de los proyectos tiene que ser continuo, en cada una de las etapas. Eso es obvio. Pero en el caso de la investigación social un problema adicional es que a menudo hay que hacerlo todo al mismo tiempo. En ciencias experimentales el calendario de las etapas sucesivas suele ser más claro (no siempre). En Sociología suele haber un momento en que parece que hay que hacerlo todo: bibliografía, entrevistas, diseño de cuestionarios, escribir, preparar el análisis, etc. Hay que trabajar al mismo tiempo con técnicas cualitativas y cuantitativas. Parece imposible dominarlo todo, incluso cuando el grupo de investigación es extenso. No queda claro si el sistema de investigación puede ser poco lineal, y más bien múltiple. Los problemas económicos y de gestión son considerables. Sobre una investigación tan vaporosa y múltiple es difícil que se puedan calcular beneficios. Además la gestión económica es dificultosa. En muchos proyectos los/as investigadores no pueden cobrar, por lo que difícilmente se les puede obligar a trabajar. Es difícil retribuir al personal, pagar cosas, conseguir equipamiento a tiempo. El pago se realiza con dificultades, trabas administrativas, y con retraso. Si se solucionase el retraso y se pudiese retribuir libremente a investigadores se habría solucionado quizás el impedimento más importante a la investigación social en la universidad.

En la investigación directa con la universidad (no así en la que se realiza a través de fundaciones para-universitarias) es difícil pagar a los/as investigadores. Se realiza algo de forma indirecta o en especie. Si se paga algo no es inmediato con lo que se incentiva mal. El sistema de control de presupuestos cree en la norma de la deshonestidad. El control del gasto no se aplica para facilitar la investigación sino para evitar el robo o el expolio. Pero dado que el mundo de la investigación universitaria es muy motivado y vocacional, la implicación de deshonestidad es doblemente humillante. Los controles son 
difíciles y sucesivos. A menudo gastos obvios no pueden ser cobrados por algún problema de contabilidad. Se admite transporte en taxi de forma limitada, aun cuando sea necesario. Pero si se quiere utilizar coche propio no se pagan gastos, ni siquiera gasolina. Realmente el sistema es un rompecabezas. Se aprende pronto a suplir deficiencias contables en unas partidas con sobrecargo en otras, o al menos con recompensas de otro tipo: asistencia a congresos, viajes pseudoprofesionales, viajes dobles, etc. El sistema se convierte pronto en ineficaz. Quizás la mejor forma de solucionar esto es que los/as investigadores tengan poder para cambiar los sistemas contables y de control presupuestario 29.

El problema es que en un grupo de investigación hay que conseguir proyectos nuevos, y realizar los antiguos; todo al mismo tiempo. Una estrategia es el banco de proyectos. Se trata de proyectos buenos que por alguna razón (todavía) no han sido financiados. Es bueno tener este banco de proyectos organizado. Quizás se podrían coleccionar esos proyectos, para ponerlos en archivo, y lograr financiación. A menudo proyectos precompetitivos pero que no obtienen financiación externa son financiados por la propia universidad. Entre las personas que realizan la investigación y las personas que dan dinero tendría que haber personas que no realizan investigación pero que la gestionan, y sobre todo que buscan recursos para las que realizan investigación. Pero pagar a estas personas supone un problema adicional, que debería de hacerse desde la propia universidad. Son personas que generan muchos más recursos que lo que supone su salario. La idea es una fundación de fundaciones, o buscadores de recursos de investigación. La idea no es nueva -pues existe en el extranjero- pero su aplicación a España es poco usual en investigación social.

El ideal es distinguir cada vez más entre el/la jefe del proyecto, la dirección de la investigación, y los/as gestores de proyecto. Esto se entiende difícilmente en una universidad donde el rector es a su vez un catedrático, y los vicerrectores (normalmente varones) a menudo también lo son. Estos profesores no enseñan, y a menudo son malos gestores. Una vez que terminan su trabajo de gestión académica y tienen que reintegrarse a la investigación en sus Departamentos las dificultades son considerables. La estructura de gestión de la universidad -desde el rector, hasta los decanos, directores de departamento, hasta jefes de estudio- se basa en profesores. Realizan una docencia limitada y les es imposible seguir con la investigación. El problema es especialmente dramático para los/as profesores-investigadores que tienen que

29 La participación de los diversos miembros del grupo de investigación es variable. El objetivo es que personas que están trabajando sobre temas solapables o similares tengan espacio y oportunidad para relacionarse. A veces todos/as participan. Otras veces nadie quiere trabajar. La investigación cuando es importante suele generar euforia, y una unión catártica de los/as miembros. Pero una investigación importante puede ser igualmente aburrida. Quizás el nivel de crítica horizontal es productivo a nivel científico, pero un exceso de democracia suele dar al traste con bastantes proyectos. A menudo nadie está realmente dirigiendo un proyecto. La continuidad puede ser llevada por un becario/a, cuyo tema de tesis coincide con el del proyecto. Esto ocurre bastante en la investigación social. 
dedicarse a la gestión de la investigación ${ }^{30}$. El número de personas implicadas en actividades de investigación disminuye. Las personas pueden dejar de investigar, o abandonar la carrera investigadora. Llegar a investigar en una etapa adulta es bien difícil. Ocurre como con el deporte o la música: conviene empezar temprano. Muchas de las personas que empiezan a investigar, o que inician una tesis, luego no siguen investigando. Esto es un problema importante en Ciencias Sociales pues la mortalidad es mayor, y hay que empezar con muchas personas para que permanezcan luego sólo unas pocas. Eso supone además un problema de costos. En algunas Ciencias Sociales (sobre todo en Economía o Derecho) las personas se cansan de ser profesores o investigadores y se van al mundo real profesional. A ello contribuye que los salarios exteriores son bastante mejores.

Se investiga poco a nivel internacional. Hay investigación competitiva a nivel nacional, pero eso suele ocultar que los niveles no son comparativos con el extranjero. Muchos proyectos de investigación de encargo (para instituciones publicas, ayuntamientos, partidos políticos) no resisten niveles internacionales de calidad. Luego no suelen dar origen a artículos en revistas reputadas, ni libros en editoriales comerciales. Es una investigación poco relevante, que no transforma la ciencia ni el avance del conocimiento. Esto no significa que sea insignificante. Mucha investigación aplicada es importante para producir un cambio en la política social, y por lo tanto es útil. Pueden ser estudios sobre pobreza, discapacidad, marginación, problemas urbanos, falta de desarrollo en una zona, problemas familiares, calidad de educación, etc. Los proyectos pueden ser de dudosa calidad científica internacional pero de utilidad mediata a nivel local.

La expresión «líneas de investigación» es poco clara en la investigación social. No es fácil explicitar líneas de investigación concretas. Pero si se analiza lo que hace un grupo es posible distinguir temas diferentes. Pero esas líneas dependen más de un investigador/a concreto, y de la forma en que define sus temas e intereses. A su vez depende de los proyecto de encargo. Un proyecto bien financiado es difícil de rechazar, y se integra en cualquier línea posible de trabajo. Son esos proyectos los que al final definen las líneas de investigación de un grupo. Si se realizase una historia natural de grupos de investigación social se notaría que los cambios en intereses son explicables a menudo por cambios coyunturales o de proyectos concretos. Al analizar retrospectivamente la carrera profesional de un/a investigador se pueden observar esos cambios debidos a accidentes financieros, cambio de residencia, de Departamento, etc. Sólo un investigador/a muy potente marca las líneas de investigación de forma consciente. Existe también el agotamiento de una línea. Todos los/as investigadores van cambiando de temas, una vez que

${ }^{30}$ El coste real de una hora de director/a de investigación, o de investigador/a, es elevado, aunque poco calculable. Se refiere a lo que vale el tiempo de una persona que obtiene proyectos, realiza investigación, escribe, $o$ analiza datos. Es preciso que la investigación a nivel intelectual sea llevada por personas que son descargadas de labores de gestión. Este es un nivel que apenas se ha llegado en nuestro país. 
han abierto brecha o han avanzado en una línea concreta, dejando el trabajo posterior a otros/as investigadores. Llama la atención que algunos investigadores formados en el extranjero y que se especializaron en temas novedosos -que además llegan a dominar- luego cambian sus intereses de investigación, y se dedican a temas distintos. No hay una explicación clara para este hecho observado claramente en la generación de los años setenta y ochenta que salieron al extranjero a especializarse en investigación social.

Contrario a lo que se cree, o dice, el problema de financiación y de medios no es el mas grave. Sí lo es el de espacios para investigar. Un buen investigador/a normalmente tiene problemas de tiempo, no de medios. No tiene tiempo para investigar, o su propio estatus elevado le recorta ese tiempo libre. Lo difícil es tener un equipo o grupo de investigación que sepa trabajar bien. Las personas más hábiles e inteligentes abandonan alguna vez el grupo, o tienen más posibilidades y ofertas para hacerlo. Varios terminan creando su propio grupo, lo cual es productivo. Los/as mejores investigadores nunca realizan investigación por dinero; ni se toman decisiones importantes de investigación por dinero. Los mejores proyectos se hacen por razones del avance del conocimiento; o menos altruistamente por motivos de estatus, prestigio profesional, contraste internacional, control de otros colegas nacionales, o por el deseo de realizar una investigación bien hecha. Es vital la consideración de los/a colegas, el peer group, o el grupo de referencia. Los proyectos de investigación revierten poco, a veces nada o incluso negativamente, en la financiación de los/as profesores. A menudo un/a investigador principal tiene que dedicar muchas horas a un proyecto, o a formar a un/a becario o investigador joven de calidad dudosa, sin que le reporte nada económicamente. Es realmente un gasto de dinero. La financiación revierte indirectamente en todos los proyectos, por ejemplo en las posibilidades de que el equipo investigador pueda viajar, asistir a congresos de forma gratuita, incluso viajar a sitios interesantes para participar en reuniones o congresos. Son beneficios indirectos, pero que no compensan la falta de motivación directa en los/as profesores que investigan.

La información es un recurso escaso, la información es poder. Los recursos de investigación y el mundo de la investigación es también un mundo secreto, parcialmente tabú, o reservado a unos/as pocos. Está lleno de siglas, comités, organismos, convocatorias, becas, fundaciones, gestoras. Toma mucho tiempo tener esa información, saber decantarla, diferenciar la que es útil y la que no. Las universidades están realizando últimamente una labor eficaz en diseminar esa información, aunque suele llegar tarde y parcialmente. Se amontona información poco útil con información importante, al mismo nivel de atención. Los grupos de investigación aprenden (tienen que hacerlo) a diferenciar lo que es importante. Las personas que están realizando investigación suelen saber bastante bien donde se pueden conseguir más recursos, y las normas (explícitas e informales) para obtenerlos. Es más difícil para un investigador novel, que está empezando, que tiende a creer en listas de fundaciones o de convocatorias de todo tipo. Pronto aprende que no todas las convocatorias son iguales, y que las que realmente le interesan son unas pocas. No se trata de hacer llegar más 
información, sino de darle peso diferencial a lo que es más productivo. Hay convocatorias importantes, y otras cuyos papeles llegan y no valen para mucho. No queda claro por qué se da tanta importancia, por ejemplo, a convocatorias de premios cuyos destinatarios se pueden señalar con los dedos de la mano. Mucha de esta información es tirada sistemáticamente. Los jefes de Departamento reciben puntualmente toda esta información, pero no siempre la distribuyen entre los/as miembros del Departamento. Creen que es una información para él (el director/a del departamento). Mucho de lo que se envía no vale la pena; pero lo importante suele desaparecer. Los buenos grupos de investigación esperan a que una convocatoria determinada se publique. Si se dan muchas becas o recursos de investigación en una convocatoria o programa afluyen investigadores a la siguiente convocatoria, con lo que descienden las posibilidades de éxito de todos/as. Quizás sería más interesante una comunicación personal a los/as propios investigadores. Las convocatorias extranjeras no suelen llegar. La participación en proyectos europeos, redes de investigadores, programa COST, etc., suele ser bastante baja en España. Muchas fuentes de financiación concretas dentro de la Comunidad Europea (para proyectos comunitarios, proyecto marco por ejemplo) no son aprovechadas, o es difícil hacerlo con los contactos que existen. A menudo los equipos que solicitan financiación europea no son necesariamente los mejores grupos de investigación nacionales. Su investigación es limitada y así sus posibilidades de obtener la financiación.

La infraestructura científica que ofrece la universidad es muy limitada, to say the least. Nada de espacio, poco de equipamiento, y algo de ordenadores, internet, e informática. Durante unos años todos los/as investigadores incluían un ordenador en el presupuesto del proyecto, y demás infraestructura. En la actualidad el problema no es la falta de ordenadores, impresoras o programas, sino de ideas. Un problema añadido es que dado que no hay espacio en la universidad para investigar los investigadores universitarios tienen que trabajar en casa, o en otras instituciones ${ }^{31}$. Empieza a haber más ordenadores que investigadores, luego ese ya no es el problema. Las bibliotecas de las universidades están dotadas, algunas, de muchos libros y revistas, pero son infiables. Falta a veces lo más importante, sobra mucho que no vale para casi nada, y las series suelen estar incompletas. La situación está mejorando mucho pero los/as investigadores no tiene confianza en los recursos de las bibliotecas generales, y consultan más las específicas o de instituciones concretas; sobre todo utilizan las estancias en el extranjero o los canales de distribución de libros extranjeros para ponerse al día. La carencia de buenas bibliotecas es uno de los problemas fundamentales de la investigación social en España en la actualidad. Muchos de los recursos de investigación sirven para comprar

31 A nadie le extrañará que el presente artículo haya sido escrito en nuestros domicilios, en ordenadores portátiles, financiado con cargo a un proyecto de investigación, en horario de fin de semana. Igualmente las tablas y gráficos se han calculado o realizado en la biblioteca, la universidad, y domicilio particular, en ordenadores de diversos origen. Muchos recursos son domésticos, y en ese sentido habría que agradecer a madres, padres, y hermanos (incluso a los hijos/as). 
libros propios, crear bibliotecas individuales, para tener ordenadores personales. Es algo que tiene poco sentido. Es una etapa que hay que superar. Una política científica adecuada debería enfrentarse con este problema y encontrar soluciones realistas. El proceso de modernización en sistemas informáticos requiere a los/as profesores un esfuerzo adicional que debe ser mejorado gracias a la dotación de personal joven especializado que ayude dentro de los grupos de investigación.

La idea de una investigación académica seria, separada de la realidad social, es cada vez más lejana. Las mejores universidades actuales realizan un esfuerzo especial por relacionar la universidad con las empresas, con el mundo real. Se entiende que la universidad tiene cada vez que investigar más en el sector privado. Muchos de los investigadores que se forman en la universidad no deberían quedarse luego en la universidad sino ir a las empresas (en sentido general, como organizaciones fuera de la universidad, privadas o públicas). España es un caso raro en donde el objetivo de la mayor parte de las personas que empiezan a hacer investigación es quedarse en la universidad. Su meta es ser profesores, ni siquiera ser investigadores/as. En parte esa conducta es una dependencia del alma mater, de falta de independencia, de carencia de roles a imitar. La universidad debe investigar para el exterior, obtener financiación fuera de la propia universidad, pero sobre todo debe de formar investigadores (doctores) para que sean contratados luego fuera de esa universidad. Es importante además evitar una endogamia excesiva, en que los doctores de una universidad se quedan luego de profesores en la misma universidad. Quizás todo esto sea más importante aun en la investigación social, que se supone debe tener una aplicación a la sociedad en que se vive.

Mucha investigación social se hace para el sector público, que suele ser el primer empleador o al menos pagador. Muchos científicos sociales se dedican a la (supuesta) resolución de problemas sociales: drogadicción, pobreza, conflictos urbanos, policía, relaciones étnicas, desigualdades sociales, salud, seguridad y asistencia social, etc. Sólo el tema de desigualdades sociales es amplísimo, y conforma el verdadero corazón de la Sociología. Cuando se habla de relaciones universidad-empresa habría que incluir específicamente las relaciones de la universidad con el sector público (las diversas administraciones públicas) ${ }^{32}$. Hay cierta tendencia a incorporarse a la investigación personas con problemas, o que por alguna razón no irían al mundo privado. Pueden ser incluso personas poco agresivas, con complejo de inferioridad, que pertenecen a clases bajas, que han sido ya becarios/as durante la carrera.

32 Se supone que la entrada en el mundo de la investigación para una persona debe de ser normalmente joven y a ser posible brillante. El objetivo fundamental de los/as profesores es conseguir para la investigación a los/as estudiantes más inteligentes y motivados (y motivarlos adicionalmente). Innovar y avanzar el conocimiento parece más difícil que la gestión, o más que la mera aplicación de la teoría a la práctica. Pero eso no es siempre así. En Ciencias Sociales es posible que se dediquen a la investigación estudiantes que no pueden encontrar nada mejor, o que no consiguen trabajo. Una universidad que no discrimina bien por notas, y que no selecciona estudiantes para el doctorado y la investigación tiene problemas. Las Ciencias Sociales son especialmente problemáticas en este punto, y no hay sistemas fáciles de solución. 
Para algunas de estas personas el realizar una carrera para ganar dinero es inadecuado. Siguen así una vocación intelectual (investigadora o docente). Tratan de devolver a la sociedad lo que les ha dado, en forma de beca o de oportunidad. Si los grupos de investigación son internacionales pueden lograr una motivación más directa, más real. En Sociología se diría que es un problema de roles. Para que una persona quiera ser investigador social necesita que existan personas que lo sean ya. Tiene que haber un modelo a quien imitar. Está claro que en investigación no pueden estar las personas que no saben o no pueden hacer otra cosa; más bien lo contrario. La forma de entrada es múltiple, pero generalmente desde los programas de doctorado, de becarios/as (que cada vez se tiende a que sean los mismos), de proyectos de investigación en marcha, de programas de postgrado (másteres). Hay pocas vocaciones tardías en la investigación.

En las Ciencias Sociales hay cada vez más mujeres. También en la universidad. Cada vez estudian más mujeres y sobre todo terminan la carrera. Empiezan el doctorado en proporciones casi iguales a varones. Terminan la tesis muchas menos, y hay menos profesoras que profesores. Las Ciencias Sociales se están feminizando, pero la docencia y la investigación es todavía bastante masculina. No digamos la proporción de catedráticas, que es bastante baja. Hay pues posibilidades para cambios considerables todavía en este proceso de feminización. Incluso algunos temas o áreas de investigación social se puede feminizar más; no sólo los estudios feministas o de mujeres que obviamente están en manos de mujeres. Los varones prosperan más que las mujeres en niveles similares, pero eso depende de factores externos: competitividad, agresividad, necesidad de obtener una retribución económica, etc. Las mujeres invierten más en educación, salvo en doctorado, pero eso está también cambiando. Los puestos importantes en la investigación social siguen siendo mayoritariamente masculinos.

La dirección de tesis es un problema artificial. Antiguamente el director/a de tesis presidía el tribunal de tesis; actualmente no puede formar parte. Pero el tribunal está propuesto por el director de tesis (a veces incluso por el doctorando/a). Se evalúa la tesis cuando ya está terminada, por lo que las críticas son de poca utilidad. Ser director de tesis es un mérito, e incluso puede tener consecuencias económicas para un profesor/a (está relacionado con los tramos de investigación, y con el plus de docencia). Pero la mayoría de direcciones de tesis no funcionan de forma adecuada. Se requeriría un estudio en profundidad para mejorar los problemas que se observan. Los/as estudiantes difícilmente se dejan dirigir. Sacar una tesis adelante es un esfuerzo enorme. Es un problema que está mal organizado, y al que habría que darle otras alternativas ${ }^{33}$.

${ }^{33}$ El tema de la compatibilidad de docencia e investigación es otro problema falso. No es que haya que pedir compatibilidad sino que una buena docencia es inseparable de la investigación. Pero también debería existir la posibilidad de una carrera investigadora en la universidad, y no sólo en el CSIC. Eso supone cambiar la estructura de la universidad y que exista una plantilla de investigadores. Se habla mucho del tema pero se ha hecho muy poco. Los problemas de aplicación son enormes. Quizás la institucionalización de grupos de investigación, consolidados, permita que existan plazas de investigador. Pero todavía parece pronto para esa posibilidad real. 
Las universidades del mundo se clasifican fundamentalmente en universidades que enseñan, y universidades que enseñan a investigar e investigan. Las mejores universidades del mundo tienen programas excelentes de docencia, pero se dedican a formar los/as investigadores y profesores (doctores) para el resto de las universidades del mundo. Son además las primeras en investigar y en hacer avanzar el conocimiento. Las del segundo grupo se dedican a reproducir ese conocimiento o a enseñarlo. Pero no suele haber universidad que no investigue algo. En el caso español eso es claro, pues apenas hay universidades sin programas de doctorado. Hay universidades que producen más títulos de doctor, o que se especializan en un tipo de carreras, pero casi todas tienen doctorados (aunque no en todas las áreas). Pero los programas de doctorado no son centrales, y ni siquiera son programas serios de educación. Están más bien para formar al personal propio, los/as jóvenes profesores ayudantes o becarios de la misma universidad. Hay excepciones, y universidades que tienen programas de doctorado exogámicos e importantes, pero son una minoría, y no se sabe durante cuanto tiempo podrán conservar esos niveles de calidad altos con la falta de recursos que van a tener. Las Escuelas Universitarias cada vez más numerosas no se dedican a la investigación ni al doctorado, sino a carreras cortas. Siguen un modelo de universidad no investigadora, sino reproductora.

El nivel de intercambio y de movilidad, asistencia a congresos, profesores visitantes, etc., aumenta. Es una tendencia imparable. Los programas europeos (Sócrates, Erasmus) han contribuido mucho a este desarrollo. Los intercambios son desiguales. Vienen bastantes colegas a investigar, pero hay muy poco españoles que realicen investigación social sobre otras sociedades. Somos estudiados pero apenas estudiamos otras culturas. La falta de investigación sobre Latinoamérica, o sobre el norte de África es llamativa. Sobre Asia apenas hay estudios. Es un intercambio desigual porque no hay buenos profesionales de las Ciencias Sociales que puedan realizar investigación competitiva en otros países. En Sociología es parte del propio objeto de estudio. El interés por los estudios comparativos es creciente.

Se entiende por «colegio invisible» (se refiere más bien a la universidad invisible) a la comunicación internacional de científicos/as, y al desarrollo de debates e ideas en torno a esa comunicación. La formación inicial española es a veces deficitaria, y no existe un bagaje teórico común con otros/as colegas. Segundo, el nivel de manejo de idiomas extranjeros es deficiente. Las carencias de profesores e investigadores para dominar el inglés es problemática. Seguramente no lo será tanto en el futuro, cuando entre una nueva generación de investigadores que sí han aprendido inglés bien. Cuando las personas no han recibido una formación básica las posibles redes de intercambio de información o de teorías no se organizan o son desiguales. Dos fenómenos han cambiado recientemente este panorama: el interés por Europa e internet. La Unión Europea esta poniendo un énfasis especial en la cooperación y movilidad en investigación, con programas como COST. Internet y correo electrónico están permitiendo una comunicación instantánea barata entre profesionales e investigadores de todo el mundo. A la larga estos dos factores van a producir transformaciones importantes en el colegio invisible. 
No hay líneas claras de investigación en los grupos de investigación. Realmente tampoco hay grupos de investigación establemente definidos. En cambio la comunidad científica internacional está sólidamente establecida. Es difícil entonces entender cómo se evalúa la investigación o cómo se mide la productividad en las Ciencias Sociales. El sistema funciona mucho mejor para las ciencias duras, en donde las revistas reputadas son conocidas incluso por sus índices de audiencia. El peer review, el sistema de reviewers, el de citations, los abstracts son poco utilizados en las Ciencias Sociales en España. El social sciences citation index incluye pocas revistas de Ciencias Sociales españolas. En Sociología en España no hay una revista profesional reconocida a nivel nacional. Lo más cercano sería la Revista Española de Investigaciones Sociológicas. En Sociología pocos investigadores publican en revistas extranjeras, o en editoriales importantes, en inglés. No se está todavía a este nivel. Algunos españoles que publican de esa forma es que realmente viven en el extranjero. Habría que hacer un esfuerzo colectivo, institucional, y de las universidades por superar ese listón. El sistema de prosperar en la vida académica española no pasa todavía por publicar en el extranjero.

En la carrera sociológica española no queda claro si es preciso investigar. Los estudiantes más brillantes pueden optar por una carrera local, bajo un mandarín, investigando una tesis al dictado, y siendo tempranamente profesores/as. Pueden optar por una carrera en el extranjero, realizando un doctorado fuera, pero teniendo luego problemas de incorporación a la vuelta. Mucho dependen -en ambos casos- de la escuela o familia sociológica en la que esa persona se incardine, e incluso de la orientación política del grupo. Además está el problema de que la investigación social puede ser ampliamente politizada, o al menos tener una identificación ideológica más o menos clara. En las Ciencias Sociales la materia de estudio es parte de la propia disciplina, con lo que los conflictos pueden ser importantes. En cualquier caso es necesario un reconocimiento de la especialización realizada en el extranjero. Las prioridades de investigación en Sociología no suelen ser realistas. Hay una verdadera lucha de intereses por definir las líneas de investigación como prioritarias. Los problemas sociales más novedosos (como drogadicción, sida, nueva delincuencia, envejecimiento) condicionan esta definición. Pero muchos de esos problemas concretos dependen de otros anteriores más complicados y difíciles de analizar: desigualdad social, estructura social, agresividad, capitalismo, paro, explotación humana, procesos de cambio social, globalización. Se requiere líneas de investigación esenciales, no necesariamente de investigación básica, pero que analicen mejor esos procesos sociales. Una creciente investigación es local -y localista- preocupada con temas mediatos, y en un entorno geográfico muy limitado. Se hace poca investigación social sobre España, y comparativa entre países. Esas son deficiencias obvias que conviene resolver. Mucha definición de líneas prioritarias es además ideológica o partidista.

La universidad es una organización que sabe definir bastante mal sus prioridades. No suele concretar líneas de expansión aunque sí de edificios o de construcción de aulas. Cuando hay dinero o recursos de investigación extraordinarios se suelen repartir equitativamente entre carreras o departamentos. 
Hay miedo por definir áreas de conocimiento que se deben desarrollar. Definir qué áreas van a recibir recursos y cuales no, dado el nivel de autoridad dentro de la universidad pública, es una actitud suicida. Puede crear conflictos de todo tipo. Se suele dejar al curso natural de la evolución o el cambio dentro de la propia universidad. La definición de prioridades científicas o investigadoras no parece ser nunca una prioridad.

\section{INVESTIGACIÓN DE LA INVESTIGACIÓN DE LA INVESTIGACIÓN}

La evaluación de la investigación sobre I+D es parte de la política científica de una universidad, y de un país. La política científica es más política que científica. Es necesaria una política científica adecuada a las necesidades de la población y a la problemática de los/as investigadores. No hay recursos para investigar todo, luego tiene que haber una planificación y evaluación de la investigación. En el caso de las Ciencias Sociales, su aplicación directa a la realidad social hace más importante esa política científica. El Plan Nacional de $\mathrm{I}+\mathrm{D}$ cambia cada varios años sus prioridades y los criterios, así como los programas nacionales (especiales o temáticos). Pero no se ofrece información de por qué se realizan esos cambios. Depende de las personas nuevas que mandan en el Plan, o en cualquier caso del Gobierno central. No es fácil demostrar lo que es más productivo a nivel de la sociedad. El objetivo obvio serían las necesidades de la población, y en consecuencia los problemas sociales, pero tampoco hay unanimidad sobre cuáles son esas necesidades, ni la mejor manera de resolverlas. Se necesita seguramente una investigación de las líneas prioritarias. Tampoco está clara la efectividad de la investigación social en los problemas de la sociedad. Por ejemplo, muchos años de investigación sobre pobreza no parecen reducirla.

Se suele afirmar que el desarrollo de la sociedad no depende de la investigación social. Pero es más bien al revés. Un país desarrollado no logra reducir los problemas sociales, e incluso aparecen otros nuevos y complicados. El sector de servicios, terciario, es cada vez más importante al menos desde la perspectiva de la economía y la población activa. Los países más avanzados o desarrollados incluyen problemas sociales «nuevos»: la nueva pobreza, nueva delincuencia, nueva drogadicción, nueva marginación, nuevas minorías, el cuarto mundo, underclass, etc. La Sociología lo que trata de investigar -tomando casi siempre el punto de vista del actor/a- son los modelos alternativos de sociedad y de organización. El objetivo fundamental de la investigación social es -mientras no se demuestre lo contrario- la disminución de las desigualdades sociales, y económicas, así como la profundización de la democracia. Afinando un poco más se trataría de la disminución de los puntos de partida de desigualdad (individual y familiar), de las diversas posibilidades de promoción de las personas, así como la evaluación de las necesidades de la población. El planteamiento de necesidades de la población y problemas de la sociedad es ya conocido en la investigación sociológica espa- 
ñola por lo menos desde el Plan CCB en los años sesenta. El desarrollo investigador de las Ciencias Sociales debe ser medido con indicadores distintos a los de otras ciencias. La vocación de la Sociología es descubrir nuevos mundos, nuevas formas de organización, y cambiar las estructuras sociales. La Sociología analiza incluso -y pone en duda- los sistemas de reproducción científica, los paradigmas dominantes, y la propia investigación social. Es un ejemplo de experto/a que analiza su propia experteza. Por eso es tan difícil ser neutral y aséptico.

Cada universidad debe elaborar su propia política científica. Otro problema es cómo se coordinan todas las universidades. Hay organismos para ello como el Consejo de Rectores. No importa tanto qué criterios de política científica tenga una universidad como que los tenga definidos en alguna parte. Es conveniente que esos criterios tengan que ver con la característica humanista de la universidad y con su carácter público/privado, aunque lo importante es que avance el conocimiento. La meta es una universidad investigadora, que no duplique el conocimiento sino que innove y avance el conocimiento. Los problemas de investigación no suelen depender del nivel de inteligencia de los/as profesores o los/as estudiantes. Fundamentalmente es un problema de infraestructura, de espacio, de equipamiento, y de organización racional de la investigación. Se requieren bibliotecas a nivel internacional, sistemas de comunicación, ordenadores. Faltan servicios, personal laboral especializado, gestores. Falta toda la organización de la investigación. No es sólo un problema de dinero o recursos, sino de tamaño, y de especialización de la investigación. La investigación no puede quedar como un apéndice de la docencia, o según el voluntarismo de un puñado de profesores y becarios/as. La universidad tiene que comprometerse a que existan recursos paralelos a los de docencia, programas de doctorado que sean realmente carreras de tercer ciclo (y no unos seminarios vespertinos), y a unos laboratorios adecuados. Mucho se ha conseguido en las ciencias duras, pero el sistema universitario ha sido poco exitoso en las Ciencias Sociales, Jurídicas, y en las Humanidades. Algunas personas consideran que la mejor política científica es la que no existe. Se puede decir lo mismo de la política demográfica. Es un tema abierto al debate. Entrar en una política de excelencia, de evaluación internacional, de producción seria de investigación requiere una exigencia organizativa considerable. La solución de institutos universitarios de investigación que planteó la reforma universitaria apenas si se ha desarrollado satisfactoriamente. Es mucho lo que queda por hacer incluso dentro del marco legal actual. Se trata de crear centros donde el progreso de las personas empleadas no dependa de la docencia enteramente sino de la investigación. Un objetivo sería crear una plantilla paralela de investigadores/as.

El nivel de investigación social es tan bajo dentro de la universidad, que las consecuencias sociales de lo que sí se investiga son mínimas. No sabemos hasta qué punto se puede cambiar la sociedad en base a estudios de investigación social. Los informes sociológicos en el mejor de los casos valen para saber quién va a ganar las elecciones (y no siempre) pero no para ganarlas. Un tema a investigar es precisamente el de investigaciones sociales que hayan 
cambiado la realidad social, y las estructuras de desigualdad en España. Lo primero que aprende un/a investigador social es que la realidad social cambia lentamente, a veces demasiado lentamente. En ese sentido la irresponsabilidad de los/as investigadores sociales es asumible. Afortunadamente la población hace poco caso de los/as expertos.

Dicho todo lo anterior hay que reconocer que hay algo mágico en ser -0 querer ser- investigador/a. Existe el placer de investigar. Es adictivo. Es un tema que sin embargo no se suele investigar, salvo desde los hombros de los gigantes (haciendo alusión al libro de Robert K. Merton). Después de explicar la precariedad de la investigación social en España, y sobre todo en las universidades, no se explica cómo todavía existen vocaciones investigadoras. $\mathrm{Si}$ se demuestra a los mejores estudiantes que investigar es atractivo, que produce placer, y que justifica una vida, es posible que convenzamos a algunos más. Se trata de que la universidad se quede - para la carrera investigadora- con los/as mejores estudiantes de su propia organización. Ese ha sido el objetivo de cualquier política científica universitaria en los últimos siglos. Lo que caracteriza a un/a profesional es un conjunto de valores básicos, común a sus otros/as colegas. Ese CVB (como se le denomina en sociología de las organizaciones) se aprende precisamente en la carrera. Lo que falta en nuestras universidades son sistemas reproductores del CVB del investigador/a. Si se repasa la lista de investigadores sociales más prominente en nuestro país se observaría que la mayoría aprendió ese CVB en el extranjero, no tanto en nuestras propias universidades. Se trata pues, last but not least, de crear un sistema de CVB que pueda ser reproducido. En las Ciencias Sociales todavía el mejor consejo a un/a joven brillante es que se vaya al extranjero, no que trabaje en un grupo investigador local.

\section{BIBLIOGRAFIA}

Almarcha, Amparo (1982): Autoridad y privilegio en la universidad española: Estudio sociológico del profesorado universitario (Madrid: Centro de Investigaciones Sociológicas), $376 \mathrm{pp}$.

Almarcha, Amparo; González, Benjamín y González, Celia (1994): «Cambio y desigualdad en el profesorado universitario", Revista Española de Investigaciones Sociológicas 66, pp. 117-139.

BECKER, Howard S., et al. (1961): Boys in White: Student Culture in Medical School (Chicago: The University of Chicago Press), $456 \mathrm{pp}$.

Bellavista, Joan (1984): Science and Technology Policy in Spain: Organisational Constraints and Potential Development (Mánchester: Manchester University), $131 \mathrm{pp}$.

Bellavista, Joan (1991): «Evaluación de la investigación social», Revista Española de Investigaciones Sociológicas 56, pp. 219-237.

Bellavista, Joan, et al. (1993): Política científica y tecnológica: Evaluación del $I+D$ en la Universitat de Barcelona (Barcelona: Universitat de Barcelona), 331 pp. Es una versión corregida de su tesis doctoral (1992) en la Universidad Autónoma de Barcelona (338 pp.). 
Ben David, Joseph (1984): The Scientist's Role in Society: A Comparative Study (Chicago: The University of Chicago Press), 209 pp. Esta segunda edición (sobre la primera de 1971) incluye una interesante introducción.

CAïs, Jordi (1997): Metodología del análisis comparativo (Madrid: Centro de Investigaciones Sociológicas), 201 pp. Es el número 21 de la colección de «Cuadernos Metodológicos».

CAmPo, Salustiano (162): «Es necesaria la Sociología?», Revista de Estudios Políti$\cos 121$, pp. 205-209.

Centro de Investigación y Documentación Educativa, Cide (1995): El sistema educativo español 1995 (Madrid: Ministerio de Educación y Ciencia), 343 pp. Especialmente el capítulo 7 «Educación universitaria», pp. 167-177, y pp. 286303.

Сово, Juan M. (1994): «Educación», pp. 1.107-1.276 en Fundación Foessa, ed., Quinto informe sociológico sobre la situación social en España: Sociedad para todos en el año 2000 (Madrid: Fundación Foessa), 2.313 pp.

DíEZ Nicolás, Juan (1971): «El científico y el intelectual en la sociedad industrial», Revista de Estudios Sociales 3, pp. 3-18.

Douglas, Mary (1986): How Institutions Think (Syracuse, NY: Syracuse University Press), 146 pp.

Folger, John K.; Astin, Helen S. y BAYER, Alan E. (1970): Human Resources and Higher Education: Staff Report of the Commission on Human Resources and Advanced Education (Nueva York: Russell Sage Foundation), 475 pp.

GabARRón, Luis R. y HERNÁNDEZ LANDA, Libertad (1994): Investigación participativa (Madrid: Centro de Investigaciones Sociológicas), $82 \mathrm{pp}$. Es el número 10 de la colección de «Cuadernos Metodológicos».

García Camarero, Ernesto y Enrique, eds. (1970): La polémica de la ciencia española (Madrid: Alianza), 557 pp.

García de Cortazar, Marisa y García de León, María Antonia (1997): Mujeres en minoria: Una investigación sociológica sobre las catedráticas de Universidad en España (Madrid: Centro de Investigaciones Sociológicas), 88 pp. Es el número 16 de «Opiniones y Actitudes».

García Ferrando, Manuel y López Aranguren, Eduardo (1991): «Experiencia de investigación social en la universidad española», Revista Española de Investigaciones Sociológicas 56, pp. 197-201.

Garvía Soto, Roberto (1993): «El problema de los objetivos en organizaciones formales». Estudios Working Papers (Centro de Estudios Avanzados en Ciencias Sociales, Instituto Juan March) junio, $72 \mathrm{pp}$.

Gobernado, Rafael (1996): «Los límites de la expansión educativa». Revista Española de Pedagogía 205, pp. 487-510.

Gobernado, Rafael y Benítez, M. Dolores (1992): «Análisis empírico del denominado 'efecto guardería' de la universidad española», en Sexta Reunión Anual de Asepelt-España, Estudios de economía aplicada. (Granada: Facultad de Ciencias Económicas y Empresariales de la Universidad de Granada), aparece en la primera sesión de «Economía de la educación».

GoHeEn, Robert F. (1969): The Human Nature of a University (Princeton: Princeton University Press), 116 pp. Está escrito por el presidente de Princeton University.

Gómez Arboleya, Enrique (1958): «Sociología en España», Revista de Estudios Politicos, pp. 47-83.

GonzÁlez Blasco, Pedro (1980): El investigador científico en España (Madrid: Centro de Investigaciones Sociológicas), $341 \mathrm{pp}$. 
Guasch, Oscar (1997): Observación participante (Madrid: Centro de Investigaciones Sociológicas), 105 pp. Es el número 20 de «Cuadernos Metodológicos».

Guillén, Mauro F. (1989): La profesión de economista: El auge de economistas, ejecutivos y empresarios en España (Barcelona: Ariel), 241 pp.

Iglesias de UsSel, Julio y Trinidad Requena, Antonio (1996): «La mujer en el sistema educativo e investigador de Andalucía», Revista de Estudios Regionales 46, pp. 181-210.

Instituto Nacional de Estadística (1996): Estadística de la enseñanza superior en España. Series de todos los niveles: Curso 1992-93 (Madrid: INE, noviembre), $213 \mathrm{pp}$. Es el anuario cuyos datos han sido utilizados para la realización del presente estudio.

InSTITUTO NACIONAL DE EsTADÍSTICA (1997): Estadística sobre las actividades en investigación científica y desarrollo tecnológico $(I+D)$ : Indicadores básicos 1994 (Madrid: INE), 100 pp.

Illich, Ivan (1972): Deschooling Society (Nueva York: Harper \& Row, Perennial Library), $186 \mathrm{pp}$.

Jencks, Christopher y Riesman, David (1977): The Academic Revolution (Chicago: The University of Chicago Press), $580 \mathrm{pp}$.

Jiménez Blanco, José; González Blasco, Pedro y López Piñero, J. M. (1979): Historia y sociología de la ciencia en España (Madrid: Alianza), 195 pp.

KAySEn, Carl (1969): The Higher Learning, the Universities, and the Public (Princeton: Princeton University Press), 85 pp. Está escrito por C. Kaysen, director del Institute for Advanced Study en Princeton.

Kennedy, Donald (1997): Academic Duty (Cambridge: Harvard University Press), $310 \mathrm{pp}$.

LATIESA, Margarita (1992): La deserción universitaria: Desarrollo de la escolaridad en la enseñanza superior. Éxitos y fracasos (Madrid: Siglo XXI, Centro de Investigaciones Sociológicas), $407 \mathrm{pp}$.

LAVE, Jean y Wenger, Etienne (1991): Situated Learning: Legitimate Peripheral Participation (Cambridge: Cambridge University Press), $138 \mathrm{pp}$.

LIPSET, Seymour M. (1976): Rebellion in the University (Chicago: The University of Chicago Press), $310 \mathrm{pp}$. la primera edición es de 1971.

Maravall, José M. (1978): Dictatorship and Political Dissent: Workers and Students in Franco's Spain (Londres: Tavistock).

Martín Moreno, Jaime y Miguel, Amando de (1079): Universidad, fábrica de parados: Informe sociológico sobre las necesidades de graduados universitarios en España y sus perspectivas de empleo (Barcelona: Vicens-Vives), 193 pp. Con la colaboración de Anna Úbeda, Maribel Hernando, y Josefina Núñez.

MEdina, Esteban (1989): Conocimiento y sociología de la ciencia (Madrid: Siglo XXI, Centro de Investigaciones Sociológicas), $345 \mathrm{pp}$.

MeYer, Marshall W. y Zucker, Lynne G. (1989): Permanently Failing Organizations (Los Ángeles: Sage).

Michavila, Francisco y Calvo, Benjamín (1998): La universidad española hoy: Propuestas para una política universitaria (Madrid: Editorial Síntesis, 1998), 318 pp.

Miguel, Amando de (1970): Informe sociológico sobre la situación social de España (Madrid: Fundación Foessa, Euramérica), 1.634 pp. Ver especialmente el capítulo 14 «Educación y ciencia», pp. 833-1.050.

Miguel, Amando de (1973): Diagnóstico de la Universidad (Madrid: Guadarrama, 223 pp. 
Miguel, Amando de (1975): «Sociology in an authoritarian society: A pessimistic reflection on the case of Spain», pp. 25-53 en Tom Bottomore ed., Crisis and Contention in Sociology (Londres: Sage).

Miguel, Amando de (1976): Reformar la universidad (Barcelona: Euros), 288 pp. En colaboración con Jaime Martín Moreno, Amparo Almarcha, Mari Sol Sanz, Anna Úbeda, y Maria Carme Maltas.

Miguel, Amando de y MARSAL, Juan F. (1978): «El raquitismo de la enseñanza de las ciencias sociales en las universidades españolas», Sistema 24-25, pp. 89-100.

Miguel, Jesús M. de (1978): Anatomía de una universidad: Para un estudio de Sociología de las Organizaciones (Barcelona: Dopesa), $139 \mathrm{pp}$.

Miguel, Jesús M. de y Moyer, Melissa G. (1979): Sociology in Spain (Londres y Los Ángeles: Sage), $299 \mathrm{pp}$.

Miguel, Jesús M. de (1990): El mito de la sociedad organizada (Barcelona: Península), $171 \mathrm{pp}$.

Mıguel, Jesús M. de (1991): «I+D en Sociología», Revista Española de Investigaciones Sociológicas 56, pp. 167-196.

Miguel, Jesús M. de (1996): Auto/biografías (Madrid: Centro de Investigaciones Sociológicas), $197 \mathrm{pp}$. Es el número 17 de la colección de «Cuadernos Metodológicos».

Miguel, Jesús M. de (1999): «Ronald G. Ehrenberg, ed., The American University: National Treasure or Endangered Species? (Ithaca y Londres: Cornell University Press).», Revista Española de Investigaciones Sociológicas.

Miguel, Jesús M. de (1998): Estructura y cambio social en España (Madrid: Alianza), $681 \mathrm{pp}$.

Miguel, Jesús M. de; Caís, Jordi; Tormos, Raül, y Vaquera, Elizabeth (2000): Excelencia: Calidad de las universidad españolas (Barcelona: Universidad de Barcelona), $432 \mathrm{pp}$.

MoncaDA, Albert (1983): Más allá de la educación (Madrid: Tecnos), 125 pp.

MonTORo, Ricardo (1981): La Universidad en la España de Franco (1939-1970): Un análisis sociológico (Madrid: Centro de Investigaciones Sociológicas), $221 \mathrm{pp}$.

MuÑoz, Emilio y ORNIA, F. (1986): Ciencia y tecnología: Una oportunidad para España (Madrid: Aguilar), $237 \mathrm{pp}$.

NIETo, Alejandro (1984): La tribu universitaria: Fenomenología de los catedráticos de la Universidad española (Madrid: Tecnos), $148 \mathrm{pp}$.

ORTEGa Y GASSET, José (1930): Misión de la Universidad (Madrid: Revista de Occidente). Se maneja aquí la cuarta edición de 1965 con el título de Misión de la Universidad y otros ensayos afines (pp. 13-78). Se trata de una conferencia «Sobre reforma universitaria», en el Paraninfo universitario, en la calle de San Bernardo, de la Universidad de Madrid.

OrRILL, Robert, ed. (1997): The Condition of American Liberal Education: Pragmatism and $a$ Changing Tradition (Nueva York: The College Board), $300 \mathrm{pp}$. Con un capítulo introductorio por Bruce A. Kimball, y el comentario de 25 expertos en educación universitaria.

Pelikan, Jaroslav (1992): The Idea of the University: A Reexamination (New Haven: Yale University Press), 238 pp. Está escrito por el presidente de Yale University.

Pérez Díaz, Víctor (1981): «Universidad y empleo», Papeles de Economía Española 8, pp. 296-319.

PerkINS, James A. (1966): The University in Transition (Princeton: Princeton University Press), 90 pp. Está escrito por el presidente de Cornell University.

Powell, Walter W. y DiMAGgIo, Paul, eds. (1991): The New Institutionalism in Organizational Analysis (Chicago: The University of Chicago Press), 478 pp. 
Ramón y CAJAL, Santiago (1941): Reglas y consejos sobre investigación científica: Los tónicos de la voluntad (Madrid: Espasa Calpe, Colección Austral), 218 pp.

Revista Española de Investigaciones Sociológicas, 24 (1983), 282 pp. Número extraordinario sobre Universidad, con artículos de Esteban Medina, Julio Carabaña, Joaquín Arango, Ricardo Montoro, Isidoro Alonso Hinojal, Amparo Almarcha, etc. Incluye una «Bibliografía sobre la Universidad 1975-1983» (realizada por A. Almarcha).

Ricoy, José M.; Guasch, M. Francisca y Clavería, Luis-Erik, eds. (1996): Fondo de Investigación Sanitaria (1988-1995): Una aproximación al análisis de un programa $1+D$ (Madrid: Ministerio de Sanidad y Consumo, Instituto Nacional de la Salud), $224 \mathrm{pp}$.

Rodríguez, Jesús, et al. (1997): «El estado de la Universidad», El País Semanal (1997), es una serie de artículos que se inicia con «1. Modernas», en el número 1.075 (domingo, 4 mayo), pp. 39-54.

Rodríguez, Josep A. (1983): «La sociología académica», Revista Española de Investigaciones Sociológicas 64, pp. 175-200.

RODRígueZ, Josep A. (1991): "Nuevas tendencias en la investigación sociológica», Revista Española de Investigaciones Sociológicas 56, pp. 203-217.

RoDriguez, Josep A., y Guillén, Mauro F. (1992): «Organizaciones y profesiones en la sociedad contemporánea», Revista Española de Investigaciones Sociológicas 59, pp. 9-18. Ver todo este número extraordinario editado por los dos sociólogos.

Romero, José L. y Miguel, Amando de (1969): El capital humano: Ideas para una planificación social de la enseñanza en España (Madrid: Confederación Española de Cajas de Ahorros), 263 pp.

SÁNCHEZ-FERRER, Leonardo (1997): «From bureaucratic centralism to self-regulation: The reform of higher education in Spain», West European Politics, vol. 20, n. 3 , pp. 164-184.

SÁNCHEZ-FERRER, Leonardo (1999): Informe sobre el sistema de gobierno de las universidades españolas basado en una encuesta a miembros del Consejo de Universidades y presidentes de Consejos Sociales (Santander: Universidad Internacional Menéndez Pelayo), $96 \mathrm{pp}$.

ShILs, Edward, et al. (1984) The Academic Ethic (Chicago: University of Chicago Press), $104 \mathrm{pp}$. Se subtitula The Report of a Study Group of the International Council on the Future of the University, publicado el año anterior en Minerva (vol. 20).

STINCHCOMBE, Arthur L. (1990): «University administration of research space and teaching loads: Managers who do not know what their workers are doing», pp. 312-340 en Information and Organizations (Berkeley: University of California Press), $391 \mathrm{pp.}$

Tena Artigas, Joaquín; Cordero, Luis y Diaz Jares, José L. 1976): La Universidad española: Datos para un problema (Madrid: Confederación Española de Cajas de Ahorros), $215 \mathrm{pp}$.

Torres, Cristóbal (1994): Sociología política de la ciencia (Madrid: Siglo XXI, Centro de Investigaciones Sociológicas), $239 \mathrm{pp}$.

Touraine, Alain (1974): The Academic System in American Society (Nueva York: McGraw-Hill), 319 pp.

Veblen, Thorstein (1968): The Higher Learning in America: A Memorandum on the Conduct of Universities by Business Men (Nueva York: Hill and Wang), 209 pp. La primera edición es de 1918.

WeBER, Max (1967): «La ciencia como vocación», pp. 180-231 en El político y el cientifico (Madrid: Alianza), conferencia original en 1919.

Wolfle, Dael (1971): The Uses of Talent (Princeton: Princeton University Press), 204 pp. 


\section{RESUMEN}

Analiza los logros y problemas de la investigación social en el sistema universitario. Se inicia con un marco de referencia que incluye el análisis de las actividades en investigación científica y desarrollo tecnológico (I+D) según los datos publicados por el Instituto Nacional de Estadística español. Se presentan cifras sobre los gastos y personal en I $+\mathrm{D}$ por Comunidades Autónomas. Luego se enfoca el caso de las Ciencias Sociales, que suponen el $9 \%$ de toda la investigación española. La segunda parte relaciona esos datos con los logros y problemas de la investigación social en nuestro país, desde la perspectiva específica de las Ciencias Sociales. Estudia el papel de la Universidad en la investigación social, y la profesionalización de la investigación, aplicado a la Sociología. Esta parte elabora la experiencias a un nivel triple: dirección de investigación, investigador, y estudiante de doctorado realizando investigación doctoral. Discute la realización de políticas científicas en las universidades españolas, así como las dificultades en establecer líneas prioritarias de investigación de cara al siglo XXI. 